\title{
Developmental Assembly of Transduction Apparatus in Chick Basilar Papilla
}

\author{
Fan Si, ${ }^{1}$ Hilary Brodie, ${ }^{1}$ Peter G. Gillespie, ${ }^{2}$ Ana E. Vazquez, ${ }^{1}$ and Ebenezer N. Yamoah ${ }^{1}$ \\ ${ }^{1}$ Center for Neuroscience, Department of Otolaryngology, University of California, Davis, Davis, California 95616, and ${ }^{2}$ Oregon Hearing Research Center \\ and Vollum Institute, Oregon Health and Science University, Portland, Oregon 97239
}

\begin{abstract}
Hair cells, the sensory receptors of auditory and vestibular systems, use a transducer apparatus that renders them remarkably sensitive to mechanical displacement as minute as $1 \mathrm{~nm}$. To study the embryonic development of the transducer apparatus in hair cells of the chick auditory papilla, we examined hair cells that have been labeled with $\mathrm{N}$-(3-triethylammoniumpropyl)-4-(4-(dibutylamino)styryl) pyridiniumdibromide, which has been shown to permeate the transducer channels. In addition, mechanotransduction currents were recorded directly using whole-cell patch-clamp techniques. The structure of the hair bundle was examined using scanning electron microscopy, and immunofluorescence labeling for myosin $1 \mathrm{c}$, myosin $7 \mathrm{a}$, and plasma membrane $\mathrm{Ca}^{2+}$ ATPase 2 was studied to determine the developmental expression of these proteins in embryonic chick papillas. We demonstrate that the transducer apparatus is assembled jointly at embryonic day 11 (E11) of the developing chick basilar papilla. The resting open probability of the transducer channels was high at E12 $(\sim 0.5)$ and remained substantially elevated at E14-16; it then declined to the mature value of $\sim 0.15$ at E21. The displacement sensitivity of the transduction apparatus, the gating force, increased from E12 to E21. Although the expression of different components of the transducer apparatus and the transduction current peaked at $\sim$ E14-16, marked refinement occurred beyond E16. For example, myosin 1c appeared diffusely localized in hair bundles from E12 to E16, but subsequently consolidated into punctate pattern. The fine temporal and precise spatial assembly of the transducer apparatus likely contributes toward the exquisite sensitivity of the transduction ensemble.
\end{abstract}

Key words: hearing; inner ear; sensory receptors; myosin; PMCA; voltage clamp

\section{Introduction}

Our perception of sound and ability to respond to linear and angular acceleration, relative to the head position, rely on the appropriate development and functions of hair cells in the inner ear. A hair cell is designed to transduce mechanical stimuli as minute as $1 \mathrm{~nm}$ into electrical responses by using its transduction apparatus, which resides in its hair bundle (Russell et al., 1989; Hudspeth, 1992). Each hair bundle consists of 30-300 stereocilia arranged in rows of increasing height. Stereocilia are connected at their tips by very fine extracellular filaments $(\sim 5-10$ $\mathrm{nm}$ in diameter) called tip links, which are stretched each time the bundle is deflected toward the tallest stereocilia (Pickles et al., 1984). Increased tension in the tip links enhances the open probability of mechanoelectrical transducer channels located close to the point of insertion of tip links at the stereociliary membrane (Assad et al., 1991; Hudspeth, 1992).

The inward transduction current that ensues from channel opening adapts to constant stimuli in a process termed adapta-

Received Aug. 13, 2003; revised Sept. 29, 2003; accepted 0ct. 6, 2003.

This work was supported by National Institutes of Health Grants DC03828 and DC04215 (E.N.Y.) and the Marriot Foundation Grant for Auditory Science, National Organization for Hearing Research. We thank Dr. E. Jones and Dr. K. Murray for their generous support by allowing us to use their confocal microscope (Olympus Fluoview). We thank Dr. N. Chiamvimonvat and members of our laboratory for their constructive comments.

Correspondence should be addressed to Ebenezer N. Yamoah, Center for Neuroscience, Department of Otolaryngology, University of California, Davis, 1544 Newton Court, Davis, CA 95616. E-mail: enyamoah@ucdavis.edu. Copyright $\odot 2003$ Society for Neuroscience $\quad 0270-6474 / 03 / 2310815-12 \$ 15.00 / 0$ tion (Eatock et al., 1987), which allows the cell to shift its responsiveness toward the position to which the bundle has been displaced. Adaptation is conferred rapidly $(\tau<5 \mathrm{msec})$ by openchannel block by $\mathrm{Ca}^{2+}$ (Wu et al., 1999; Holt and Corey, 2000) and slowly $(\tau>30 \mathrm{msec})$ by $\mathrm{Ca}^{2+}$-dependent motor proteins such as myosin 1c (Yamoah and Gillespie, 1996; Holt et al., 2002) and myosin VIIa (Kros et al., 2002), or perhaps both (Vazquez and Yamoah, 2002). Apart from its direct action on the transduction channel, $\mathrm{Ca}^{2+}$ helps to maintain the integrity of tip links because it has been shown previously that $\mathrm{Ca}^{2+}$ depletion using the $\mathrm{Ca}^{2+}$ chelator BAPTA results in breakage of the tip links (Assad et al., 1991). Moreover, $\mathrm{Ca}^{2+}$ regulates the restoration of tip links after breakage (Zhao et al., 1996). Recently it has been demonstrated that the activity of plasma membrane $\mathrm{Ca}^{2+}$ ATPase (PMCA) $\left(\mathrm{Ca}^{2+}\right.$ pump) regulates hair bundle $\mathrm{Ca}^{2+}(\mathrm{Ya}-$ moah et al., 1998; Vazquez and Yamoah, 2002). Thus the transduction apparatus, at a minimum, consists of the transduction channel, the tip link, which is either the gating spring that directly controls channel opening or is located in series with it, the adaptation motor, which ensures that transduction channels are optimally poised to detect the most minute forces, and a $\mathrm{Ca}^{2+}$ pump, which regulates hair bundle $\mathrm{Ca}^{2+}$ and the extracellular microdomain $\mathrm{Ca}^{2+}$ concentrations necessary to optimize the magnitude of transducer currents (Yamoah et al., 1998; Vazquez and Yamoah, 2002). To achieve its remarkable sensitivity, a hair 
cell must assemble its transduction apparatus with nanometer-scale precision.

The timing and mechanisms of the functional assembly of the transduction apparatus are unknown. Detailed morphological studies in development and regeneration of hair cells in the chick have been conducted that show the systematic elongation of stereocilia and the formation of the staircase pattern in hair bundles (Tilney and DeRosier, 1986; Corwin and Cotanche, 1988; Tilney et al., 1988; Cotanche and Corwin, 1991); however, the exact timing for the maturation of the transduction apparatus is not known. In the present study, we used immunohistochemical, histological, fluorescent confocal microscopy of $\mathrm{N}$-(3-triethylammoniumpropyl)-4-(4-(dibutylamino)styryl) pyridiniumdibromide (FM1-43) loading of hair cells (Gale et al., 2001) and electrophysiological approaches to determine the time of appearance of the transduction machinery of hair cells from the midsection of the abneural portion of the chick basilar papilla. Our results showed that developmental assembly of the transduction apparatus entails multiple steps that are reflected in the magnitude and kinetics of transducer currents.

\section{Materials and Methods}

Isolation of the chick basilar papilla. The present investigation conforms to the Guide for the Care and Use of Laboratory Animals published by the National Institutes of Health (NIH publication 85-23, revised 1985) and was performed in accordance with the guidelines of the Animal Care and Use Committee of the University of California, Davis.

Chicks at different stages of embryonic development and at day 21 (E21), the day of hatching, were killed. Chicken eggs were staged as described (Hamburger and Hamilton, 1992) and incubated at $37^{\circ} \mathrm{C}$ in a Marsh automatic incubator (Lyon Electric, Chula Vista, CA). Basilar papillas were isolated as described previously (McNiven et al., 1996; Zhao et al., 1996). The preparations were dissected from E7-21 embryos and transferred briefly to Minimum Essential Medium (Invitrogen, Carlsbad, CA). The tegmentum vasculosum and the tectorial membrane were removed after exposure of the organ to $100 \mathrm{mg} / \mathrm{l}$ subtilisin (protease type XXIV; Sigma, St. Louis, MO) for 10 min. Chick basilar papillas were stored in a $37^{\circ} \mathrm{C}$ incubator before subsequent manipulations. All experiments were performed within $1 \mathrm{hr}$ of isolation at room temperature $\left(22-23^{\circ} \mathrm{C}\right)$. Unless indicated otherwise, the experiments were performed on hair cells from the midsection of the abneural portion of the chick basilar papillas.

FM1-43 labeling of hair cells. The lipophilic dye FM1-43 (Molecular Probes, Eugene, OR) has been shown to enter hair cells via transducer channels (Gale et al., 2001), suggesting that FM1-43 labeling can be used as a measure of the resting activity of transducer channels. Stock solutions of $3 \mathrm{~mm}$ FM1-43 were dissolved in dimethyl sulfoxide and kept at $-20^{\circ} \mathrm{C}$. The basilar papilla was placed on Cell-Tak-coated glass coverslips in an experimental chamber containing $\sim 1.5 \mathrm{ml}$ chicken saline and viewed using an Olympus Fluoview Laser Scanning Confocal Microscope equipped with the appropriate optics and filters (excitation 488 $\mathrm{nm}$, emission $600 \mathrm{~nm}$ ) using $10 \times$ dry and $40 \times$ water immersion lenses. A series of experiments were performed whereby the basilar papilla was exposed to $3 \mu \mathrm{M}$ FM1-43 for $10 \mathrm{sec}$ and immediately washed three times in oxygenated chicken saline containing (in $\mathrm{mm}$ ): $155 \mathrm{NaCl}, 6 \mathrm{KCl}, 4$ $\mathrm{CaCl}_{2}, 2 \mathrm{MgCl}_{2}, 5 \mathrm{HEPES}$, and 3 glucose at $\mathrm{pH}$ 7.4. For another set of experiments, local perfusion of FM1-43 (3 $\mu \mathrm{M})$ was applied for $5 \mathrm{sec}$ to with rhodamine-phalloidin.

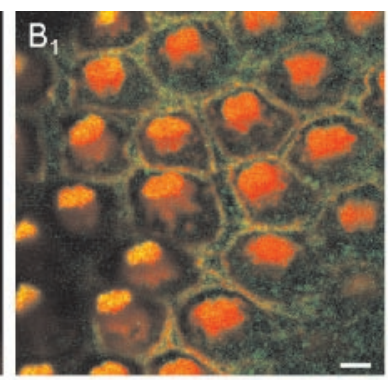

Myosin 1c

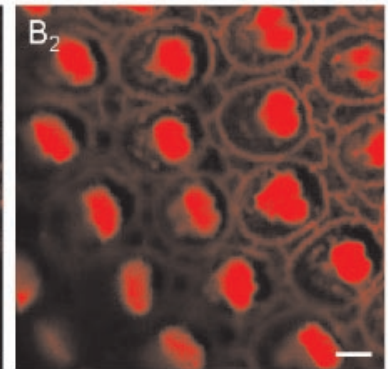

Control

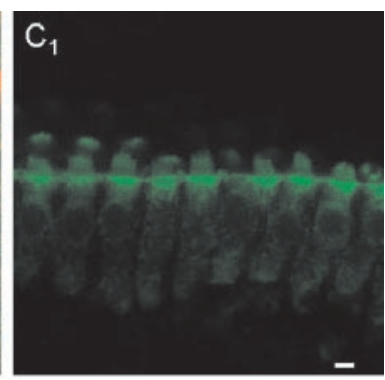

Myosin VIla

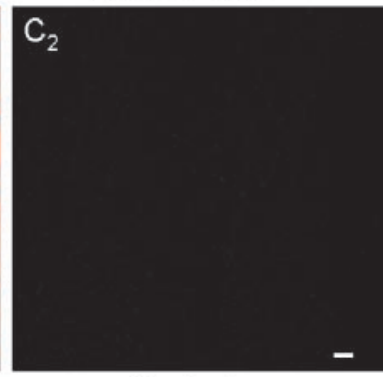

Control
Figure 1. Immunofluorescence localization showing specific labeling of PMCA2, myosin 1c, and VIlla in hair cells from the chick basilar papillas. $A_{1}, B_{1}, C_{1}$, Positive labeling with PMCA2, myosin-1C, and VIla, respectively. The secondary antibody was conjuthe apical aspect of the hair bundles. In addition, myosin-1c labeling was observed at the surface of supporting cells. Positive conjugated phalloidin showed no positive staining except for actin labeling $\left(A_{2}, B_{2}\right)$. Note that in $C_{1}$ and $C_{2}$ actin was not labeled

the apical surfaces of hair cells using glass tubing with $\sim 0.7 \mathrm{~mm}$ internal diameter that was coupled to a perfusion fast-step device (Perfusion Fast Step, SF 77B; Warner Instrument, Hamden, CT). The bath chamber was perfused continuously with oxygenated chicken saline. For those experiments of FM1-43 loading during mechanical stimulation, the basilar papilla was viewed with an upright Olympus BX 50WI microscope equipped with epifluorescence optics and FITC filters (excitation 488 $\mathrm{nm}$, emission $600 \mathrm{~nm}$ ) using $40 \times$ water immersion lenses. Images were captured $10 \mathrm{sec}$ after dye application using a QICAM monochrome 10bit charge-coupled device camera (QImaging; Burnaby, British Columbia, Canada) and the Qcapture 2.60 software. The fluorescence intensity was measured from single hair cells using the Fluoview software (Olympus, Tokyo, Japan). Semiquantitative analysis of the fluorescence intensity was analyzed with the NIH image J software. All acquisition parameters were fixed for the experiments, allowing comparison between different preparations. Nonspecific background fluorescence was measured and subtracted from the signal to give a value for the fluorescence intensity in a gray scale arbitrary unit. For bath-application experiments, confocal images were obtained at a single focal plane of hair cells after 10 sec exposure to FM1-43; however, for local perfusion experiments ( $5 \mathrm{sec}$ exposure to the dye), stacks of images were obtained at three different focal planes (apical hair bundles, cuticular plate, and basal pole; $Z$ stacks) of the hair cell over a $70 \mathrm{sec}$ period. The sampling interval between stacks was $5 \mathrm{sec}$.

Immunocytochemistry. Chick basilar papillas were fixed with $4 \%$ paraformaldehyde for $1 \mathrm{hr}$, washed, and then permeabilized in $1 \%$ Triton X-100 for $30 \mathrm{~min}$. In another set of experiments, individual hair cells were isolated from basilar papillas using methods described previously (Zhao et al., 1996). For isolated cells, $2.5 \%$ paraformaldehyde was used to fix the preparation. Next, the tissues or cells were incubated in a blocking solution ( $1 \%$ bovine serum albumin and $5 \%$ goat serum) for $30 \mathrm{~min}$, followed by an overnight incubation $(\sim 12 \mathrm{hr})$ with one or more of these antibodies: (1) monoclonal antibody directed against PMCA2 (Affinity Bioreagents, Bolder, CO), (2) anti-myosin 1c (Garcia et al., 1998; Cyr et 
al., 2002), and (3) anti-myosin VIIa (T. Hasson, University of California, San Diego) at a dilution of 1:100. Basilar papillas were incubated in secondary antibodies (goat anti-mouse or goat anti-rabbit conjugated to fluorescein, or both) for $3 \mathrm{hr}$, washed, and viewed with a Zeiss LSM 510 confocal microscope. Actin in stereociliary bundles was detected with rhodamine-labeled phalloidin (Sigma). Although the antibodies have been shown to be effective in cross-reaction experiments with their corresponding antigens in several species (Hasson et al., 1997; Dumont et al., 2001; Cyr et al., 2002), we performed control experiments to ascertain the specificity in chick hair cells using antigenic peptides, secondary antibodies, and rhodamine-labeled phalloidin. As shown in Figure 1, the antibodies for PMCA2, myosin 1c, and myosin VIIa yielded specific reactivity toward hair-cell proteins.

Scanning electron microscopy. Chick basilar papillas were fixed with $2 \%$ glutaraldehyde and $1 \%$ tannic acid for $4 \mathrm{hr}$ at $\sim 4^{\circ} \mathrm{C}$ and postfixed in $1 \%$ $\mathrm{OsO}_{4}$ for $1 \mathrm{~min}$. The samples were dehydrated with an acetone series (30, $50,70,80,95$, and $100 \%$ ), critical-point dried from liquid $\mathrm{CO}_{2}$, sputtercoated with gold-palladium, and examined using a scanning electron microscope (Phillips XL30 TMP; FEI/Phillips Inc., Hillsboro, OR; University of California, Davis Electron Microscopy Facility).

Whole-cell transducer current recording. Beginning from the time of appearance of FM1-43 loading to E21 (day of hatch), transducer currents from single hair cells from the midsection of the abneural portion of intact basilar papillas were recorded using a perforated-patch variant of the whole-cell patch-clamp recordings and a calibrated pressure-clamp (fluid jet) system (Saunders and Szymko, 1989) to displace hair bundles. The bath solution contained (in mM): $165 \mathrm{NaCl}, 3 \mathrm{KCl}, 1 \mathrm{CaCl}_{2}, 10$ HEPES, and 5 glucose, $\mathrm{pH} 7.4$ with $\mathrm{NaOH}$. The tips of the electrodes were filled with a solution containing (in mM): $130 \mathrm{CsCl}, 10 \mathrm{HEPES}, \mathrm{pH} 7.3$ with $\mathrm{CsOH}$. To gain electrical access to the cells, electrodes were backfilled with solution containing (in $\mathrm{mm}$ ): $130 \mathrm{CsCl}, 1 \mathrm{CaCl}_{2}, 10 \mathrm{HEPES}$, and amphotericin $240 \mu \mathrm{g} / \mathrm{ml}$, pH 7.3 with $\mathrm{CsOH}$ (Rodriguez-Contreras and Yamoah, 2001, 2003). To ensure that recordings were in the perforated-patch mode instead of whole-cell mode, the backfilled solution of the patch electrode contained $1 \mathrm{mM} \mathrm{Ca}^{2+}$. A switch from the perforated-patch to whole-cell mode resulted in rapid cell death because of $\mathrm{Ca}^{2+}$ toxicity. Series resistance (5-10 M $\Omega$ ) was compensated (nominally $70-80 \%$ ). Liquid junction potentials were recorded and adjusted as described previously (Rodriguez-Contreras et al., 2002). Transducer currents were amplified with an Axopatch 200B amplifier (Axon Instruments, Foster City, CA) and filtered at a frequency of $2 \mathrm{kHz}$ through a low-pass Bessel filter, and data were stored in a computer using an analog-to-digital converter (Digidata 1200; Axon Instruments) sampled at $5-10 \mathrm{kHz}$. Voltage-dependent outward $\mathrm{K}^{+}$currents were suppressed using pipette solution containing $\mathrm{Cs}^{+}$ions and by holding the cells close to the equilibrium potential of $\mathrm{K}^{+}$(approximately $-80 \mathrm{mV}$ ).

Analysis was performed using pClamp8 (Axon Instruments) and Origin software (Microcal Software, Northampton, MA). The peak transducer current $(I)$ for each step displacement $I(X)$ was expressed in the form of the probability of channel opening $\left(P_{\mathrm{o}}\right)$ with equation $P_{o}=$ $1 /\left[1+e^{-z(X-X o) /(k T)}\right]$ to obtain single-channel gating force, $z$, and the displacement at $50 \%$ open probability, $X o$, at each embryonic stage and hatching. Unless indicated otherwise, all averaged and normalized data are presented as means $\pm \mathrm{SD}$. The statistical significance of observed differences between groups of cells or between different embryonic stages of development was evaluated using a two-tailed Student's $t$ test; $p$ values are presented in the text and figure legends, and statistical significance was set at $p<0.05$.

\section{Results}

FM1-43 loads hair cells in chick basilar papilla more rapidly via transducer channels than by endocytosis

The lipophilic dye FM1-43 permeates mechanoelectrical transducer channels in inner hair cells of mice (Gale et al., 2001). By contrast, in other cell types, the dye has been shown to enter cells by endocytosis (Cochilla et al., 1999; Griesinger et al., 2002). We demonstrate in Figure 2 that although the influx of FM1-43 into chicken hair cells may occur via endocytosis and transducer
Cyto $B$

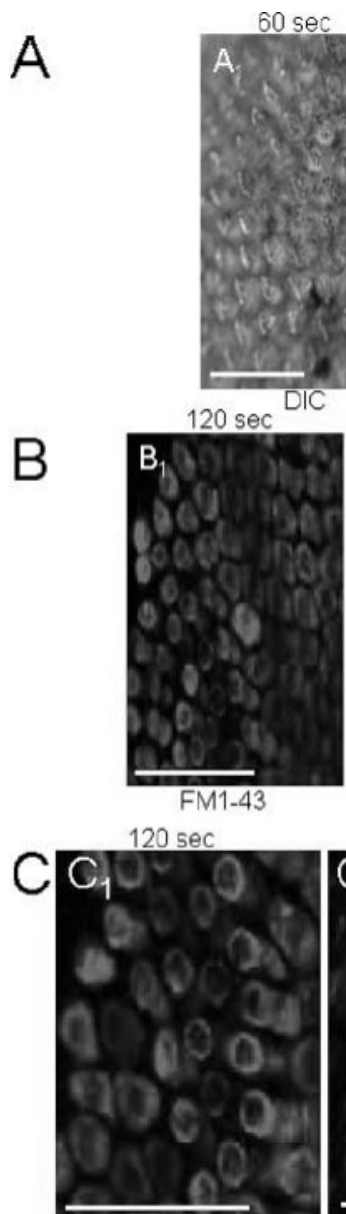

sec

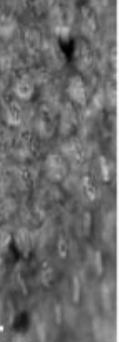

$\mathrm{D}$

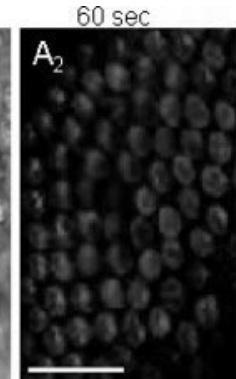

$60 \sec ^{\mathrm{FM} 1-43} 120 \mathrm{sec}$

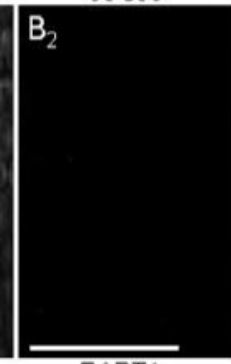

BAPTA $120 \mathrm{sec}$

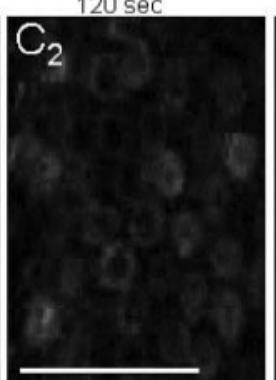

BAPTA

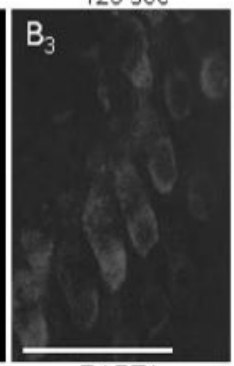

BAPTA

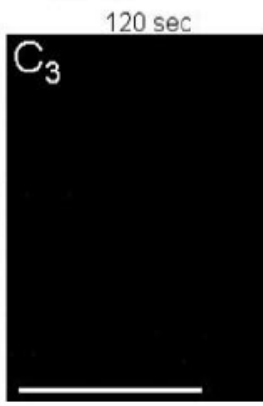

Cyto B+BAPTA
Figure 2. FM1-43 loads hair cells rapidly via transducer channels and slowly through endocytosis. $A$, Confocal images of apical aspects of a chick basilar papilla (E21) showing a DIC image (left); $A_{1}$ and the corresponding fluorescence image after 10 sec exposure to FM1-43 $\left(A_{2}\right)$, detected at $600 \mathrm{~nm}$ (image at level of cuticular plate). $B_{1}$, Fluorescence images obtained at the level of the cuticular plate show intense labeling. $B_{2}$, A longitudinal section through the length of hair cells of a BAPTA-treated preparation after a 60 sec exposure to $3 \mu \mathrm{m}$ FM1- 43 dye shows that the dye-loading was blocked. $B_{3}$ In contrast, dye loading was detected after $120 \mathrm{sec}$ exposure to $F M 1-43 . C_{1}$, Cytochalasin B-treated basilar papilla shows intense staining after 120 sec exposure to FM1- 43 (image taken at the level of the cuticular plate). $C_{2}$, Faint staining of hair cells in BAPTA-treated preparation after $\sim 120$ sec exposure. $C_{3}$, Treatment with both BAPTA and cytochalasin $B$ abolished the dye loading completely. Summarized densitometry data from the confocal images as in $A_{2}-C_{3}$, normalized against control (maximum $=100 \%$ ) and $t$ test determined against controls are as follows: 60 sec images: control (\%), $97 \pm 6(n=$ 7); BAPTA-treated, $2 \pm 5(n=8 ; p<0.001)$; cytochalasin-treated, $91 \pm 8(n=4 ; p=0.12$, NS); 120 sec images: control, $95 \pm 10(n=6)$; BAPTA-treated, $18 \pm 11(n=7 ; p<0.01)$; cytochalasin-treated, $76 \pm 12(n=6 ; p<0.05)$; BAPTA- and cytochalasin-treated, $1 \pm 3$ $(n=5 ; p<0.0001)$

channels, the kinetics of endocytosis is exceedingly slow compared with the influx via transducer channels. Shown in Figure 2, $A_{1}$ and $A_{2}$, are differential interference contrast (DIC) photomicrographs of the chick basilar papillar (E21) and the corresponding fluorescence image taken at the level of the cuticular plate after a $60 \mathrm{sec}$ exposure to FM1-43, respectively. To distinguish between the transducer channel- and endocytosis-specific component of the entry of FM1-43 into hair cells, we blocked the channel by breaking tip links with BAPTA and endocytosis with cytochalasin B (Assad et al., 1991; Zhao et al., 1996; Cochilla et al., 1999). Figure $2 B_{1}$ shows an image obtained at the level of the cuticular plate after a $120 \mathrm{sec}$ application of the dye, illustrating 
intense staining of hair cells. In contrast, in BAPTA-treated epithelium, there was no staining at all levels of hair cells after $\sim 60$ sec of FM1-43 exposure (Fig. $2 B_{2}$ ). Moreover, as shown in Figure $2 B_{3}$, there was faint staining of hair cells in the BAPTAtreated preparation only after $\sim 120 \mathrm{sec}$ application of the dye, which was in stark contrast to the intense staining observed in cytochalasin B-treated hair cells (Fig. 2C $C_{1}$ ). On the other hand, the faint staining remaining after BAPTA treatment was abolished completely by cytochalasin B after $\sim 120$ sec exposure, suggesting that some dye may enter hair cells through endocytosis (Fig. $2 C_{1}-C_{3}$ ). Within the time course of $\sim 60 \mathrm{sec}$, however, FM1-43 dye entry into hair cells is mediated mainly by transducer channels. Furthermore, using the transduction channel blocker dihydrostreptomycin (DHS) (Meyers et al., 2003), we show that FM1-43 fluorescence was abolished $60 \mathrm{sec}$ after application of dye (Fig. 3). Moreover, faint fluorescent staining became apparent $120 \mathrm{sec}$ after application of FM1-43.

The extent of FM1-43 dye loading at the apical versus basal portion as well as neural and abneural aspects of the basilar papilla was assessed. During development, there were no quantitative differences in the static and dynamic measurement of dye loading between hair cells in the neural and abneural portions of the sensory epithelia (Fig. 4A). By contrast, apical hair cells showed robust staining compared with basal hair cells, and the differences were quantitatively significant (Fig. $4 B$ ).

\section{Properties of FM1-43 loading}

Using a modified version of the protocol used to load hair cells in the mouse cochlea (Gale et al., 2001), FM1-43 was perfused locally at the apical aspects of hair cells of a E21 chicken basilar papilla, and images of serial optical sections were taken at three focal planes, at level of the hair bundles, $L_{1}$, cuticular plate, $L_{2}$, and basal pole, $\mathrm{L}_{3}$, in $5 \mu \mathrm{m}$ intervals. The time course of FM1-43 dye loading was monitored at the three levels of hair cells. The data suggest that the first appearance of the dye is at apical hair bundles, followed by the cuticular plate and the base; this result implicates the transducer channels as the primary port of entry of the dye into hair cells after brief exposure. Figure 5 shows characteristic chronological images from the three defined levels at $0-70 \mathrm{sec}$ after $5 \mathrm{sec}$ exposure to $3 \mu \mathrm{M}$ FM1-43. Z-stack images were taken at the three defined levels in 5 sec intervals (Fig. $5 A$ ). The dynamics of partitioning of the dye into the membrane of the stereocilia and the cytoplasm were similar to that reported for the hair cells from the mouse organ of Corti (Gale et al., $2001)$. The time constants $(\tau)$ of dye loading were 7,12 , and 17 sec at the bundle, cuticular plate, and basal pole levels, respectively (Fig. 5B).

\section{FM1-43 loading of hair cells of acutely isolated chicken} basilar papillas begins after E10

If FM1-43 dye entry into hair cells after brief exposure is mediated through transducer channels open at rest, then the dye loading should provide an accurate measure of the appearance and timing of expression of functional transducer currents during development. Using this reasoning, we examined FM1-43 dye loading of hair cells from the midsection of the abneural portion of basilar papillas at different embryonic stages. A $10 \mathrm{sec}$ bath
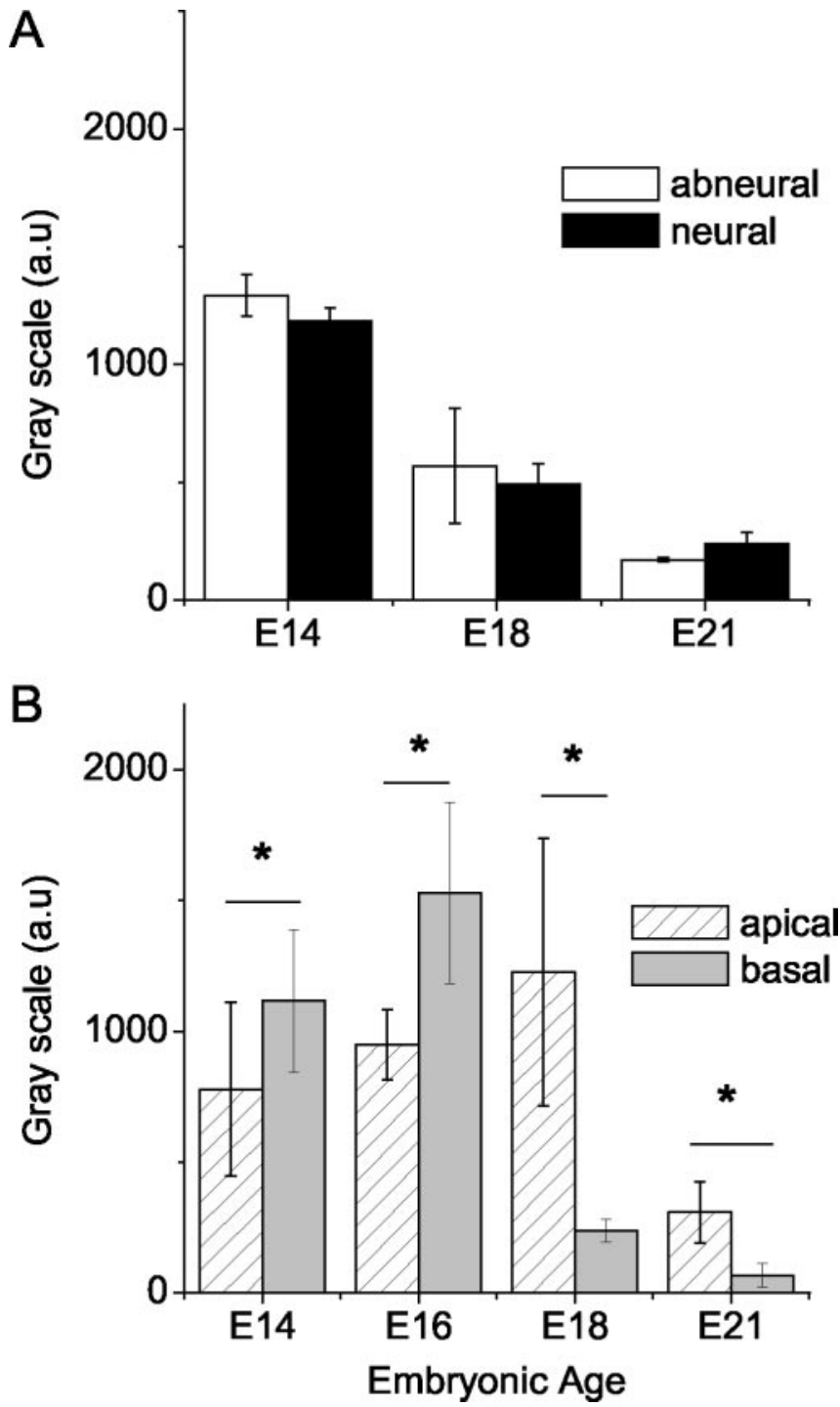

Figure 4. Differences in the development of transduction as indexed by FM1-43 dye loading at the abneural and neural sides of the papilla as well as apical versus basal segments of the chick cochlea. $A$, Summarized densitometry data of mean pixel intensity comparing abneural and neural hair cells $(n=7)$. There were no significant differences $(p>0.05)$ in the dye loading between abneural and neural hair cells for data collected at E14, E18, and E21. $B$, Comparison of dye loading in apical versus basal end of chick cochlea sampled $(n=10)$. Asterisks indicate embryonic stages during which significant differences $(p<0.05)$ in FM1-43 dye loading were recorded between apical and basal hair cells. 

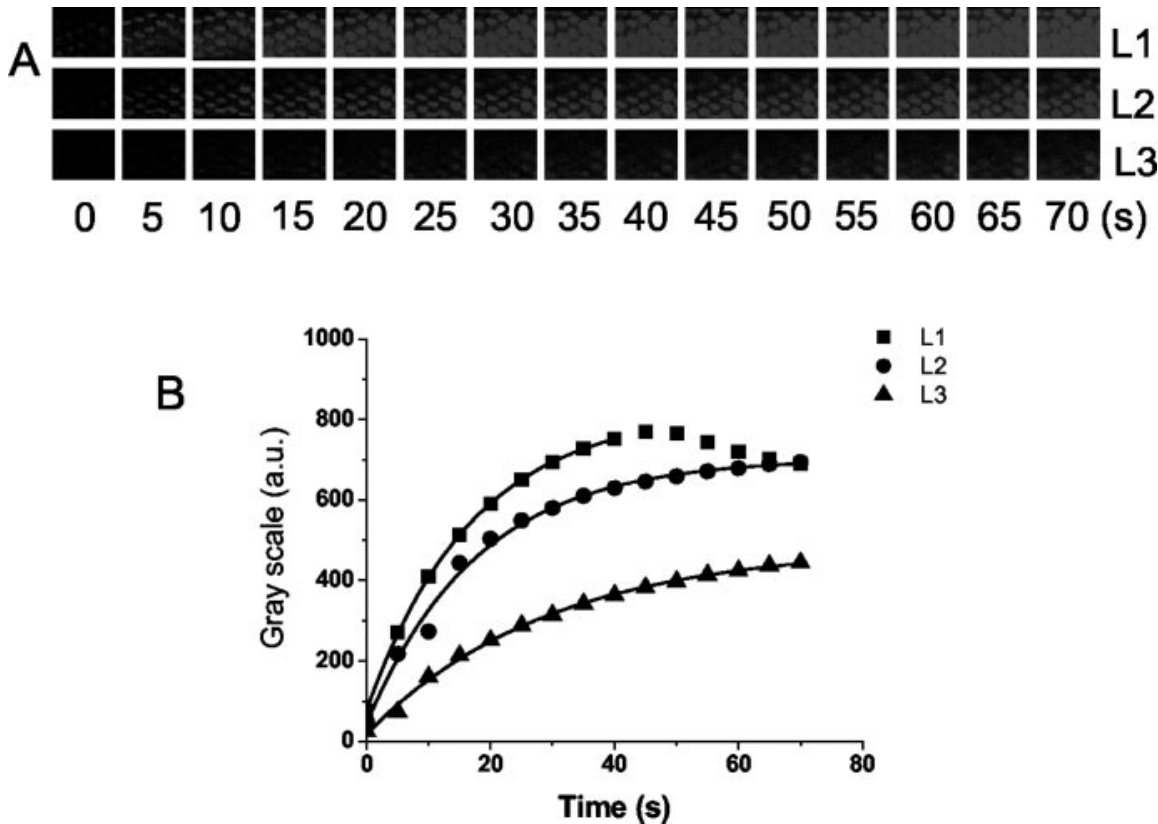

Figure 5. Time course of FM1-43 dye loading. $A$, A series of images taken at the time points indicated at the three focal levels $L_{1}, L_{2}$, and $\mathrm{L}_{3}$ referring to apical, cuticular plate, and basal levels, respectively. Time 0 indicates the onset of dye application ( $3 \mu \mathrm{m}$ lasting for $5 \mathrm{sec}$ ). The frame is an area measuring $90 \times 55 \mu \mathrm{m}$. The top row, $L_{1}$, shows consecutive images of the bundles of stereocilia at the surface of the hair cells in which a transient peak of dye labeling is observed. The middle row, $\mathrm{L}_{2}$, shows consecutive images taken at a focal plane close to the cuticular plate at the apical pole of the cell. Dye loads into this region rapidly and remains sustained. The bottom row, $L_{3}$, shows images taken at the basal pole of the cell. The dye enters the apex aspects of the cell before being visualized at the basal pole. The approximate time is indicated in seconds. $B$, The change in fluorescence at the three focal levels as a function of time (adjusted for the interval between frame-capture at each level). Frames were taken at the midsection of the abneural segment of the basilar papilla, and this loading pattern is observed at other locations as well. Dye enters hair cells at the bundle level $\left(\mathrm{L}_{1}\right)$ first; the dye is subsequently found at the level of the cuticular plate $\left(L_{2}\right)$ and then is seen finally at the level close to the base of the cell $\left(L_{3}\right)$. The change in fluorescence was fitted with an exponential function, and the time constants $\left(\tau\right.$, in sec) of FM1 -43 dye loading at $L_{1}, L_{2}$, and $L_{3}$ were 7,12 , and 17 . Mean $\tau$ values at $L_{1}, L_{2}$, and $L_{3}$ were $6.5 \pm 1.8,11.9 \pm 2.8$, and $18.3 \pm 4.6(n=9)$.
A

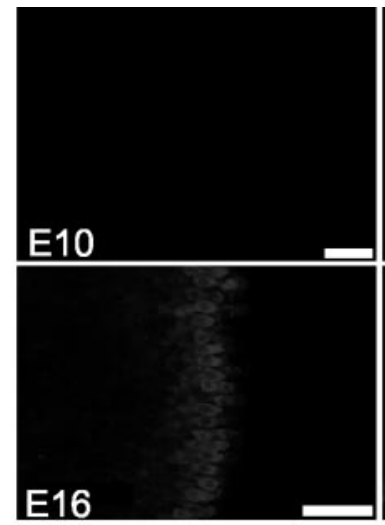

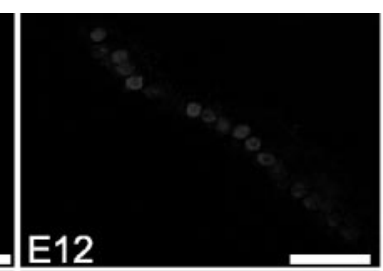

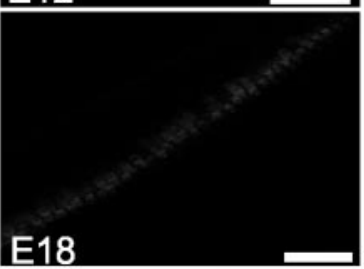

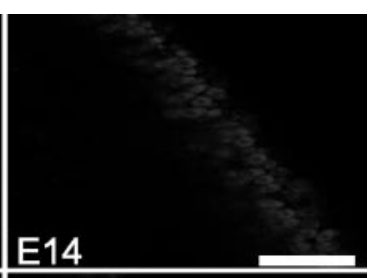
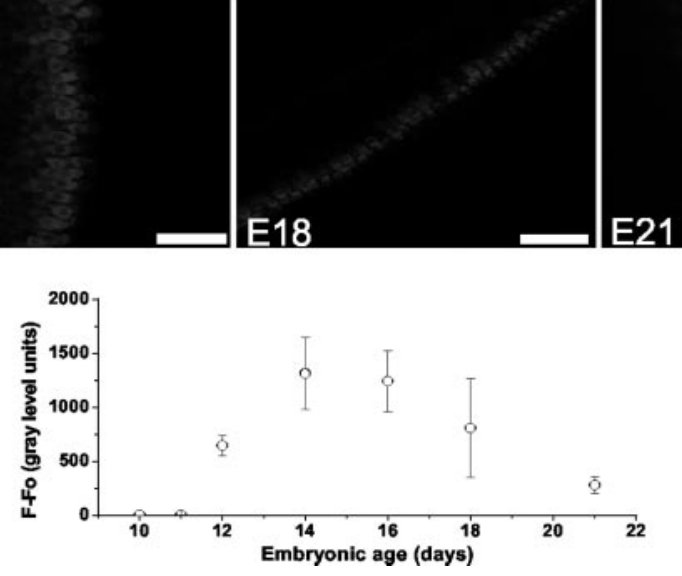

Figure 6. Genesis and development of transductionas measured by FM1-43 dyeloading from E10 to E21. A, Images were taken using fixed acquisition parameters from the midsection of the abneural segment of basilar papillas at E10, E12, E14, E16, E18, and E21. Dye loading was elicited after 10 sec bath application of $3 \mu \mathrm{m} \mathrm{FM1-43.} \mathrm{B,} \mathrm{Summary} \mathrm{data} \mathrm{of} \mathrm{the} \mathrm{development} \mathrm{of} \mathrm{dye} \mathrm{loading} \mathrm{measured} \mathrm{from}$ the midsection of the abneural segment of basilar papillas. Dye loading was observed initially and faintly at E11 and became robust atE12. The intensity of labeling peaked at E14-16 and declined at E21. The number of preparations $(n)$ used to generate the curves at various ages were $n=5,10,8,9,11,11$, and 9 for E10, E11, E12, E14, E16, E18, and E21, respectively. application of the dye resulted in labeling of hair cells from acutely isolated basilar papillas from E11 to E21 but not E10 (Fig. $6 A)$. Dye loading was faint at E11 and became more intense at E12, reaching a maximum intensity at E14-16, and declined to $\sim 20 \%$ of the peak values at E21 (Fig. 6 B). We monitored and compared the kinetics of FM1-43 dye loading after local perfusion at the apical aspects of hair cells from the midsection of the abneural side of basilar papillas from isolated basilar papillas from E12 to E21 as described in Figure 5. Strong labeling was seen first at the hair bundle level, and the dye partitioned itself into the membrane and diffused across the cell. Persistent staining was seen at the level of the hair bundle and then the cuticular plate followed by the base at embryonic ages E12-21 (Fig. 7A).

The signal at the bundle level dropped gradually, whereas staining at the cuticular plate and base levels was sustained (Fig. 7B). The $\tau$ of dye loading became increasingly rapid from E12 to E16 and then declined at E18 and E21. Moreover, the enhanced absolute levels of fluorescence intensity at E12-16 raised the possibility that the open probability of transducer channels at rest at these embryonic stages is relatively high compared with E18 and E21. Similar trends of $\tau$ of dye loading were seen at the level of the cuticular plate and base of hair cells (Fig. 7B), reflecting the apical to basal influx of the dye into hair cells. The rate $(1 / \tau)$ of dye loading increased from E12 to E14 and peaked at E16 and then declined at E18-21 (Fig. 8). The distinct nature of the FM1-43 dye loading of hair cells at different stages of embryonic development suggested that the magnitude and kinetics of transducer current vary according to the age of the embryo. Moreover, FM1-43 dye loading reflects the open probability $\left(P_{\mathrm{o}}\right)$ at rest and the number of functional transduction channels. We attempted to disentangle the two factors by applying saturating positive displacement to approximate $P_{\mathrm{o}}$ to 1 (albeit caveats associated with adaptation) to assess the development of functional transduction channels. As shown in Figure 9, the FM1-43 fluorescence increased from E12 to E21, suggesting qualitatively that the number of functional transduction channels increased with age.

Transducer currents in developing hair cells is observed first at embryonic age E12

To examine whether FM1-43 loading in developing hair cells coincides with the appearance of transducer currents, and to obtain direct evidence for the initiation of 
A

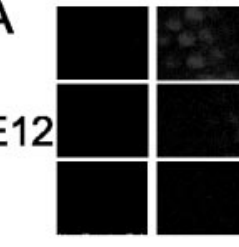

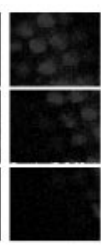
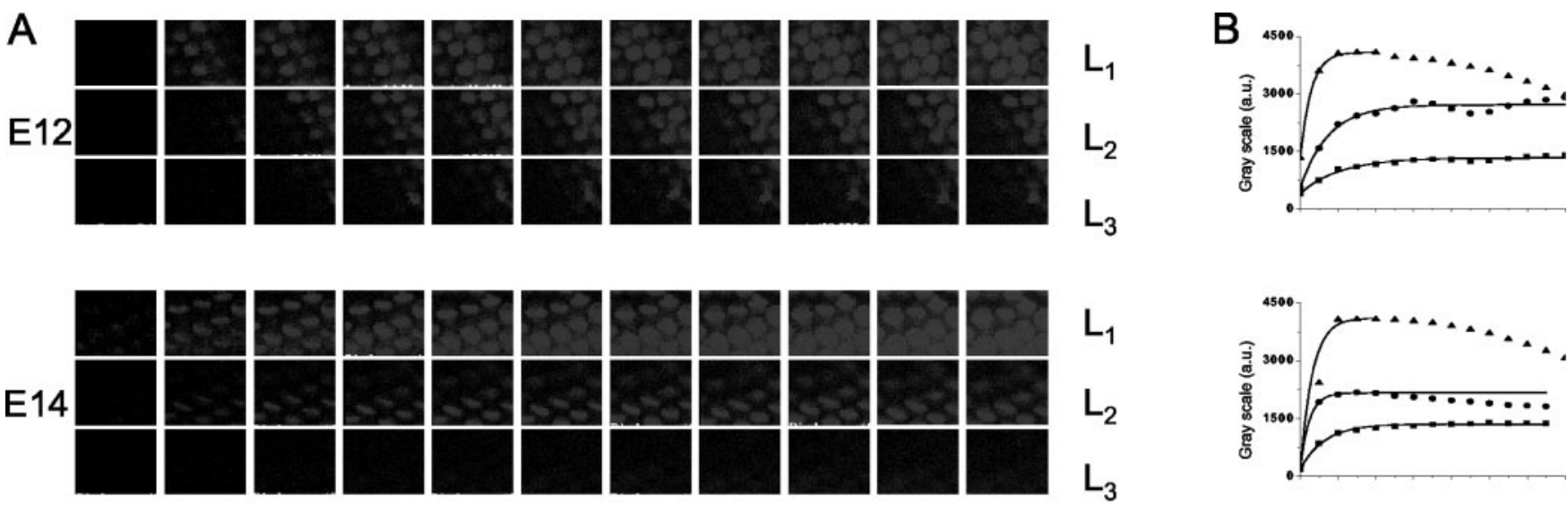

$L_{1}$
$L_{2}$
$L_{3}$
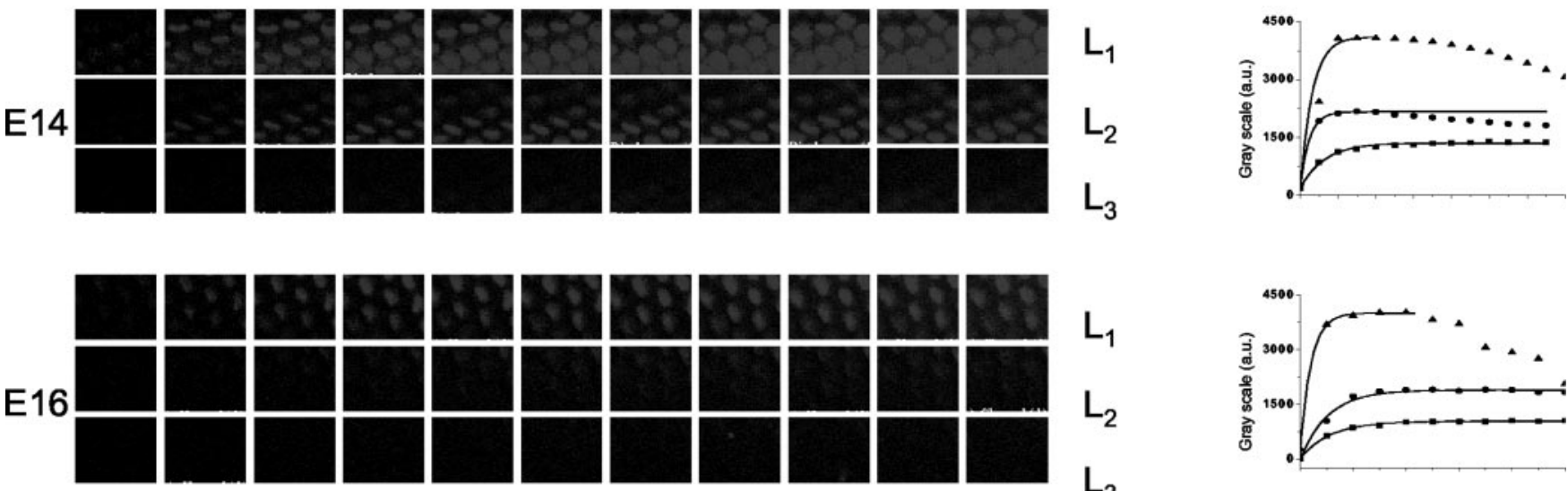

$L_{1}$
$L_{2}$
$L_{3}$
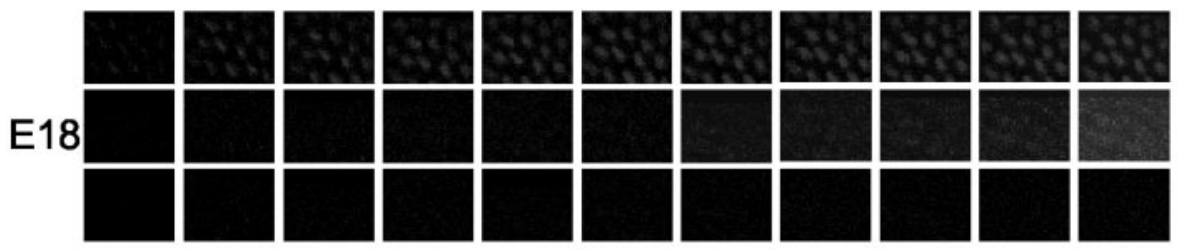

$L_{1}$
$L_{2}$
$L_{3}$
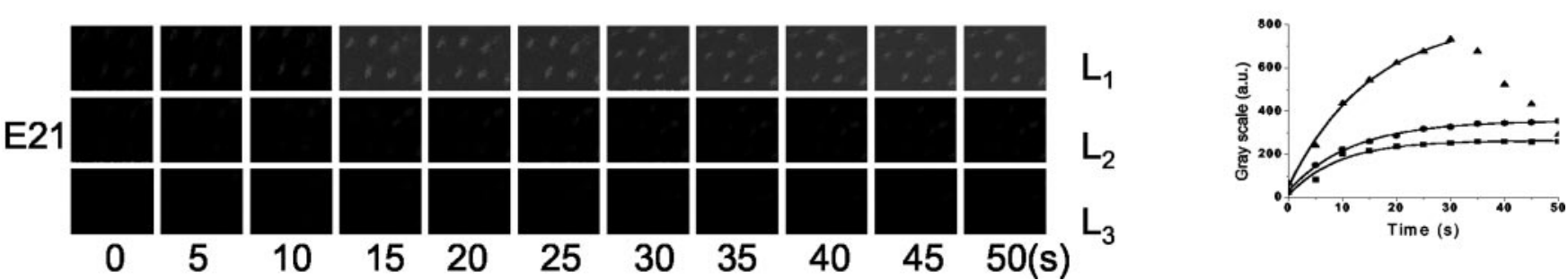

Figure 7. Comparisons of time course of FM1-43 dye loading at the midsection of the abneural segment of the chick basilar papillas at E12, E14, E16, E18, and E21. $A$, Images were captured at three focal planes at the levels $\left(\mathbf{A}, \mathrm{L}_{1} ; \mathbf{O}, \mathrm{L}_{2} ; \mathbf{\square}, \mathrm{L}_{3}\right)$ of the hair bundle, the cuticular plate, and the basal pole. The interval between frames was 1.6 sec. $B$, The changes in fluorescence have been fitted with exponential function. The $\tau$ values (in seconds) at $\mathrm{E} 12$ for $\mathrm{L}_{1}, \mathrm{~L}_{2}$, and $\mathrm{L}_{3}$ were 2.8, 7.5, and 10.6; at E14, 3.2, 4.2, and 6.5; at E16, 2.1, 5.2, and 5.6; at $\mathrm{E} 18,9.1,18.8$, and 21; and at E21, 15.1, 11.8 , and 19.4, respectively (number of preparations at each embryonic stage, $n=11$ ).

mechanoelectrical transduction, we recorded the transducer currents from hair cells using the perforated-patch variant of the whole-cell patch-clamp technique. Hair bundles were displaced with a calibrated pressure-clamp (fluid jet) system (Saunders and Szymko, 1989). Positive and negative displacements of the hair bundles along the axis of mirror symmetry yielded inward and outward current traces (Fig. 10A). The total currents at E12, E16, and E21 were $98 \pm 9 \mathrm{pA}(n=6), 259 \pm 62 \mathrm{pA}(n=16)$, and $185 \pm$ $39 \mathrm{pA}(n=22)$, respectively. Of the hair cells from this segment of the basilar papillas (midsection of the abneural portion), the displacement-open probability $\left(D-P_{\mathrm{o}}\right)$ relations exhibited two obvious features (Fig. $10 \mathrm{~B}$ ). First, there was a gradual shift of the $D-P_{\mathrm{o}}$ curves from left to right as the animals matured. At E12, the mean $P_{\mathrm{o}}$ at zero displacement was $0.51 \pm 0.12(n=4)$ compared with $0.30 \pm 0.14(n=8)$ at E14, $0.2 \pm 0.05(n=7)$ at E16, and $0.15 \pm 0.07(n=7)$ at E21. Last, a two-state Boltzmann fit to the $D-P_{\text {o }}$ curves revealed that the gating force, $z$, which reflects the displacement sensitivity of the transduction apparatus (Hud- speth, 1992), increased from E12 (14 $\pm 3 \mathrm{fN}, n=4)$ to E21 (36 $7 \mathrm{fN}, n=7 ; p<0.05)$.

Development of hair bundles and appearance of tip links To crosscheck whether the appearance of stereocilary bundles and tip links matches the observed transducer current, we prepared the chicken's hearing organ for scanning electron microscopy to assess hair bundle morphology and the number and orientation of tip links. Consistent with a previous report (Cotanche and Corwin, 1991), the stereocilary bundles assumed a staircase configuration by E12 (Fig. 11A), and there was systematic pruning of microvilli on the apical aspects of the basolateral membrane as can be seen in E16 (Fig. 11 B). By E21, only stereocilia are found on the surfaces of hair cells. Over a time period of $10 \mathrm{~d}$ (E12-21), the number of stereocilia per cell increased by approximately three- to sixfold, and they were consolidated into a cohesive bundle (Fig. 11). Because the stereocilia are somewhat splayed at E12, the tip links appeared stretched (Fig. $11 \mathrm{~B}$, inset). 


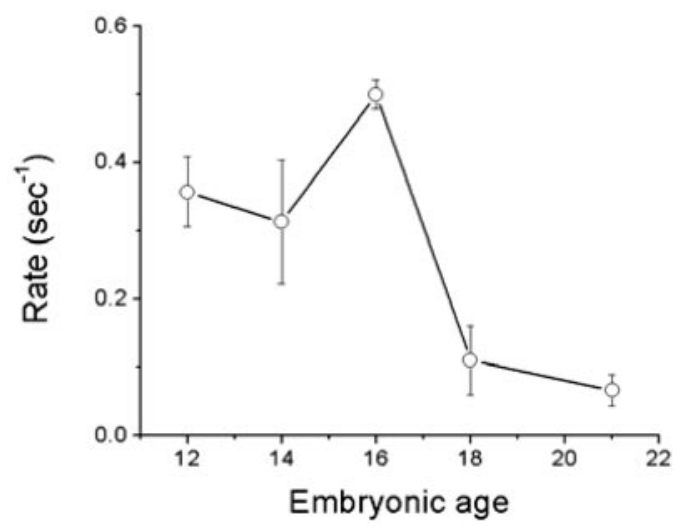

Figure 8. The rate $(1 / \tau)$ of dye loading as a function of embryonic age assessed from E12 to E21. Data were pooled from 11 cochleas at each embryonic age. The rate of FM1- 43 dye loading into hair cells increased from E12 to E16 and then declined at E18 and E21.

As depicted in Figure $12 B$, the distance between stereocillia per bundle size decreased from E12 to E21. Tip links are oriented in series with the transduction channels (Kachar et al., 2000), and this may raise the possibility that the increased resting tension may produce the enhanced $P_{\mathrm{o}}$ of the transducer channels at zero displacement (Fig. 11B). In addition to typical tip links, which run along the axis of mirror symmetry within the bundle (Pickles et al., 1987), there were linkages at the tips of stereocilia that did not run parallel to the axis of mirror symmetry called angled tip links (Zhao et al., 1996). The angled tip links may also gate transducer channels (Denk et al., 1995). The proportion of angled tip links to normal tip links increased from E12 to E16 by $\sim 2.2$-fold and then declined at E21 by $\sim 1.9$-fold of the peak value (Fig. $12 A)$.

\section{Expression of Myosin 1c, VIIa, and PMCA2}

The gating force of transducer channels is imparted by myosin $1 \mathrm{c}$ (Hudspeth and Gillespie, 1994; Yamoah and Gillespie, 1996) or in conjunction with myosin VIIa (Kros et al., 2002). In addition, PMCA2 may calibrate the $P_{\mathrm{o}}$ at rest by regulating hair bundle $\mathrm{Ca}^{2+}$ and the extracellular microdomain $\mathrm{Ca}^{2+}$ concentration (Fettiplace, 1992; Yamoah, 2001); we assessed the developmental expression of these transduction components. The expression of myosin $1 \mathrm{c}$ coincided with the developmental stage when transducer currents were first observed at E12 (Fig. 13). As reported previously in amphibian and mammalian hair cells, the expression of myosin 1c was restricted to the tips of the hair bundles (Gillespie et al., 1993). A semiquantitative analysis of fluorescence intensity of myosin 1c labeling shows that the expression of the protein increased from E12, peaked at E15, and remained relatively stable through E21 (data not shown). We determined the pixel intensity of myosin $1 \mathrm{c}$ labeling from the midsection of the abneural portion of basilar papillas at difference embryonic stages and normalized it against the peak value at E15 (1.0). At $\mathrm{E} 12, \mathrm{E} 14, \mathrm{E} 15, \mathrm{E} 17$, and $\mathrm{E} 21$ the ratios were $0.69 \pm 0.11,0.79 \pm$ $0.09,0.91 \pm 0.06,1.0 \pm 0.08,0.81 \pm 0.10$, and $0.83 \pm 0.08(n=$ 9 ), respectively. At higher magnification, longitudinal sections through the hair bundles revealed that myosin 1c labeling initially appeared relatively diffusely along the length of the hair bundles from E12 to E15. However, from E17 to E21, the labeling gradually consolidates into punctate patterns at the tips of hair bundles (Fig. 14), similar to that seen in bullfrog saccular hair cells (Gillespie et al., 1993). In addition, myosin 1c immunoreactivity
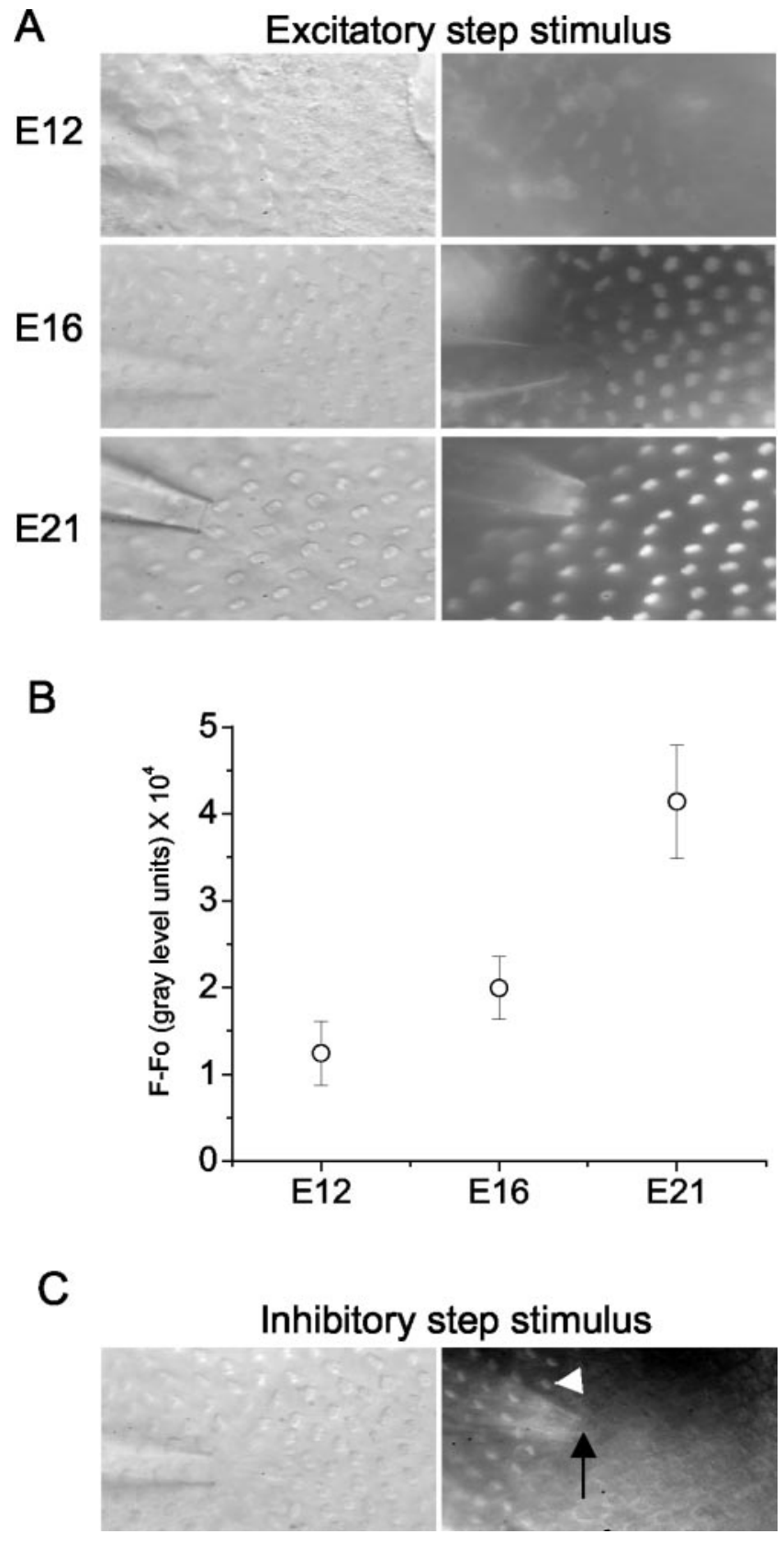

Figure 9. Development of the number of transduction channels per cell from the midsection of the abneural segment of basilar papilla as measured by FM1 -43 dye loading during saturating excitatory stimuli. $A$, Images were taken using fixed acquisition parameters at E12, E16, and E21 after 10 sec bath application of $3 \mu \mathrm{m}$ FM1-43 while a continuous positive displacement was delivered from the fluid jet (pressure clamp). B, Summary data of the development of dye loading during saturating excitatory stimuli measured from the midsection of the abneural segment of basilar papilla. The intensity of labeling increases with the age ( $n=6$ for E12, E16, and E21). Fluorescence intensities of 12 cells right in front of the pipette tip were measured, and nonspecific background fluorescence in the hair cell area displaced with a continuous inhibitory stimulus (Fig. 90 ) was measured and subtracted from the signal to give a value for the intensity of fluorescence in gray scale arbitrary units. C, Hair cells displaced with a continuous inhibitory stimulus showed no dye loading, whereas cells (white arrowhead) more remote to the pipette tip (black arrow) did load with the dye.

on the apical aspects of supporting cells increased from E15 to E21 (Fig. 13).

In contrast to the expression of myosin-1c, which overlaps with the appearance of transducer currents, myosin VIIa was observed earlier at $\sim$ E7. To compare the distribution of myosin 


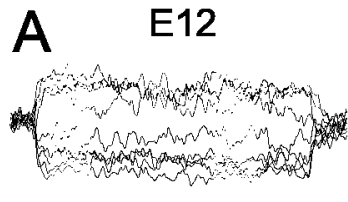

$\frac{50 \mathrm{pA}}{100 \mathrm{~ms}}$

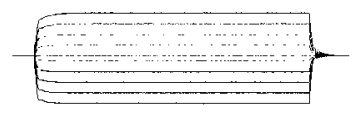

E12

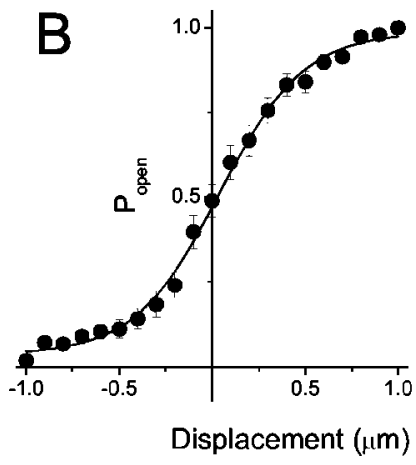

E14
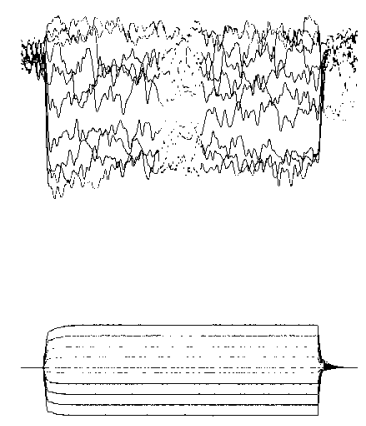

E14

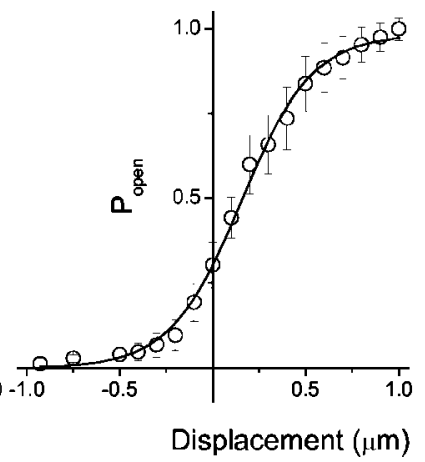

E16
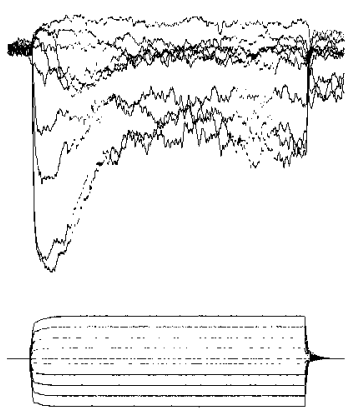

E16

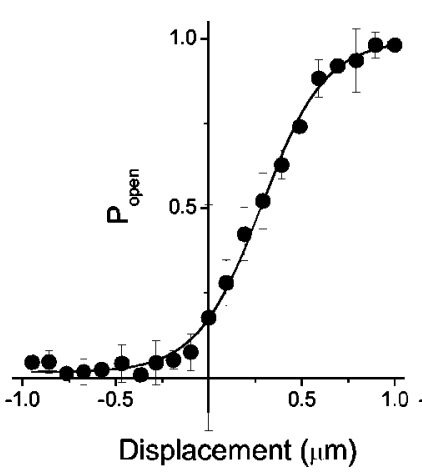

E21
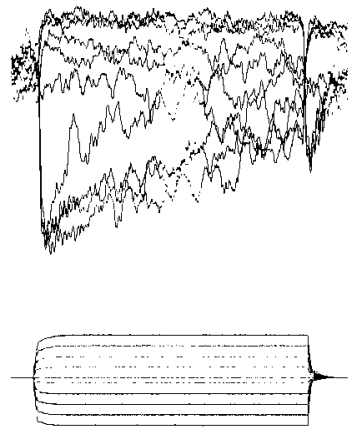
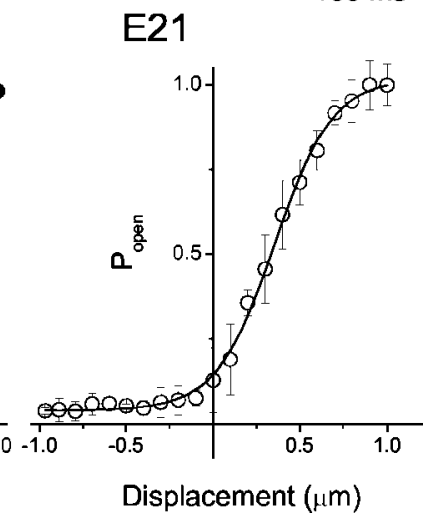

Figure 10. Mechanoelectrical transduction currents appear at E12 in acutely isolated basilar papilla hair cells. $A$, Currents were elicited from hair cells at the midsection of the abneural segment of basilar papillas from E12, E14, E16, and E21. The apparent displacement ( $X$ ) of hair bundles from the fluid jet (pressure clamp) as calibrated using simultaneous recordings captured on a video monitor is shown below the traces. Cells were held at $-80 \mathrm{mV}$ in the perforated-patch configuration. The magnitude of the total transduction current increased from E12 to E16 by approximately twofold and declined to $\sim 1.5$-fold the peak value. $B$, Instantaneous displacement-response relationships from the mean data from five cells from E12 and E14 and seven cells from E16 and E21 are shown. Error bars are omitted for clarity. The data were fit with a Boltzmann function and $P_{\text {open }}$ at rest shifted from $\sim 0.5$ at E12 to $\sim 0.15$ at E21. The gating force ( $z$ ) increased by approximately twofold from E12 to E21. At E12, E14, E16, and E21 the values for $z$ were $14 \pm 3, n=4 ; 18 \pm 5, n=7 ; 25 \pm 9, n=7 ;$ and $36 \pm 7, n=7$, respectively.

VIIa labeling with hair cells from other systems (Hasson et al., 1997), we performed the experiments on isolated hair cells from the midsection of the abneural portion of the basilar papillas. The expression pattern of myosin VIIa from E10 to E21 is shown in Figure 15. Myosin VIIa immunoreactivity appeared as diffuse staining at the basal region of the hair bundles and at the cuticular plate. In contrast, in late phases of embryonic development, it appeared to be associated with the basolateral membrane. Like myosin 1c, the appearance of PMCA2 immunoreactivity coincides with the development of transduction (Fig. 16).

\section{Discussion}

The temporal overlap of rapid FM1-43 dye loading and the appearance of transducer currents in the developing hair cell from the chick cochlea (E12) support the hypothesis that the dye enters hair cells through transducer channels (Gale et al., 2001). For prolonged exposure ( $\geq 2 \mathrm{~min}$ ), however, the dye also traverses hair cells through endocytosis (Ashmore and Richards, 2002). Thus the duration of application of FM1-43 is critically important in unraveling transducer channel- and endocytosismediated mechanisms in hair cells. No detailed reports have appeared previously on the development of transducer current and the apparatus that confers it. The appearance of transducer current coincides with the expression of myosin 1c, PMCA2, and tip links. This is consistent with the model that the mechanoelectrical transducer channel in hair cells requires a set of regulatory proteins (apparatus) to control its open probability (Vazquez and Yamoah, 2002). In contrast, stretch-activated channels, found ubiquitously in cells, rely on mechanical stress of the plasma membrane for activation (Wu et al., 2003). We observed the following findings in hair cells from the midsection of the abneural side of basilar papillas. (1) FM1-43 loading and measurable transducer current can be recorded at E12 from acutely isolated chick cochlea. (2) The resting open probability of the transducer channels appeared significantly higher at E12 ( 0.5) (Fig. 10 B) and remained substantially elevated at E14-16 until it declined to the matured value of $\sim 0.15$ at E21 (Zhao et al., 1996). (3) The displacement sensitivity of the transduction apparatus, gating force, $z$, increased from E12 to E21. (4) The expression of the transducer apparatus and current peaked at $\sim$ E14-16 and declined slightly at E21; however, interpretation of data based on the magnitude of transduction current should be handled with caution because of the tendency of the current to run down at different experimental conditions. It is unknown whether hair cells at different embryonic stages have varied susceptibility to current rundown. Nonetheless, the data showed that the transduction apparatus undergoes marked refinement beyond E16. This is exemplified by the initial diffused expression of hair bundle myosin 1c from E12 to 16 and subsequent consolidation into punctate labeling. (5) In contrast to myosin 1c and PMCA2, the expression of myosin VIIa precedes the appearance of transducer 


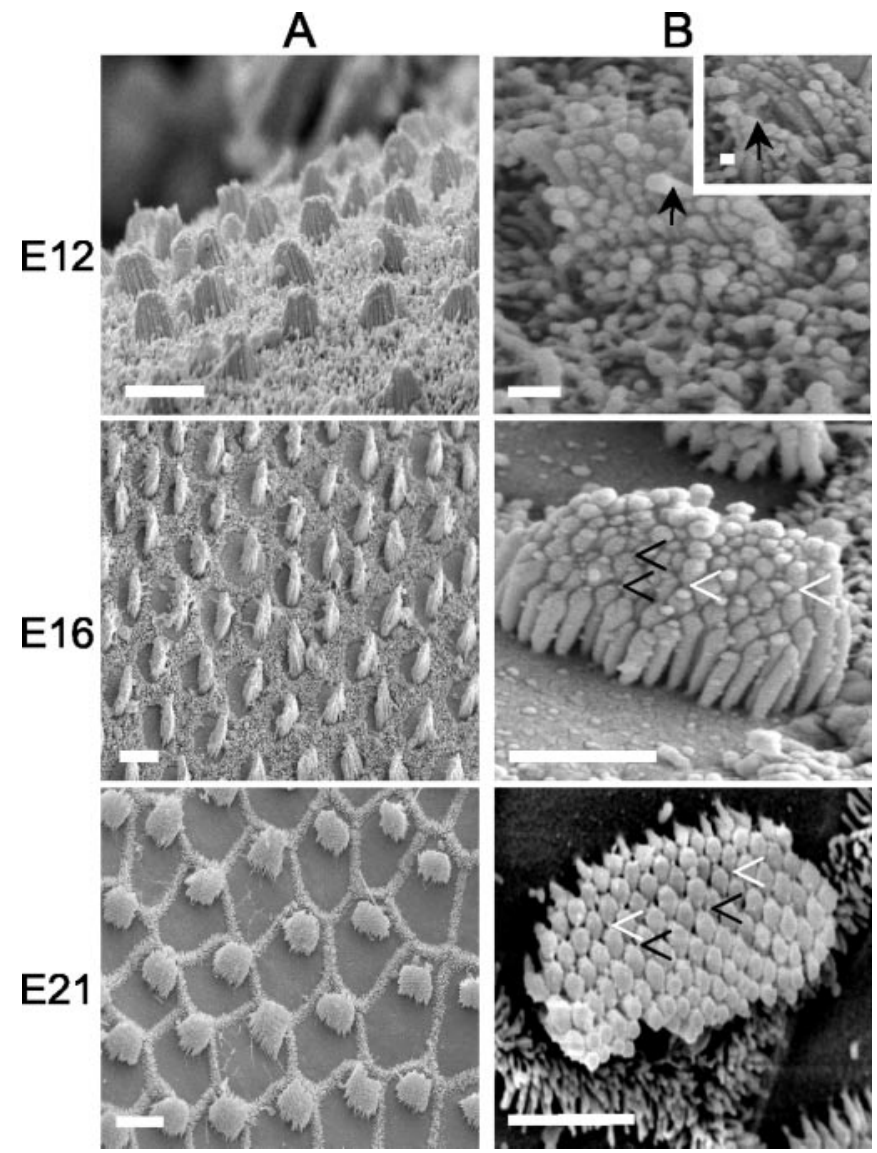

Figure 11. Scanning electron photomicrographs of hair bundles of the chicken basilar papillas from E12 to E21. All photomicrographs are derived from the midsection of the abneural portion of the basilar papillas, from the base to the apex. $A$, Scanning electron micrographs showing the apical surfaces of hair cells. The hair cell stereociliary bundles are organized in an orderly hexagonal array. Scale bar, $10 \mu \mathrm{m}$. B, Higher magnification photomicrographs showing the orientation of tip links. Open arrowheads (in solid black) indicate angled tip links, and arrowheads (in solid white) show normal tip links. Solid arrows show splayed stereocilia and tip link; the inset is a high magnification of an image at E12.Scale bars: E12, $2 \mu \mathrm{m} ; \mathrm{E} 16,4 \mu \mathrm{m} ; \mathrm{E} 21$, $4 \mu \mathrm{m}$.

currents. Myosin VIIa may serve not only as a hair cell marker but also supports other functions, e.g., structural functions. Thus it is not surprising that myosin VIIa expression occurs earlier than the other components of mechanoelectrical transduction. Consistent with FM1-43 loading and direct measurement of transducer currents, the hair bundles from E12 to E14 appeared slightly splayed, raising the possibility that the resting tension of the transduction apparatus is elevated at rest at early embryonic development. The present data were acquired from hair cells in the abneural portion of the basilar papilla. This region is populated by short hair cells, which receive primarily efferent innervation. Although the precise function of these hair cells is not known, they may be involved in the generation of some form of hair cell motility. Thus the transduction apparatus that is characterized in this study may be used, in fact, for the generation of force within the cochlea rather than afferent sensory transduction.

Our functional data show clearly that robust transducer currents can be recorded on E12; in addition, faint FM1-43 dye loading could be seen on E11, which matches well with a previous report that evoked cochlear nucleus activity begins at E11 (Saunders et al., 1973). Thus the birth of mechanoelectrical transduction and neurotransmission in hair cells may occur at a similar
A

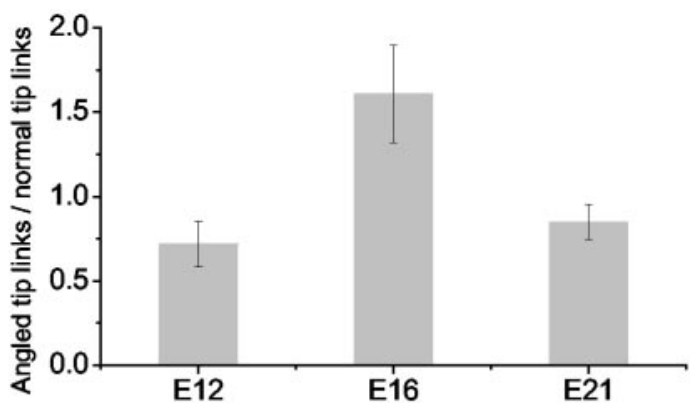

B

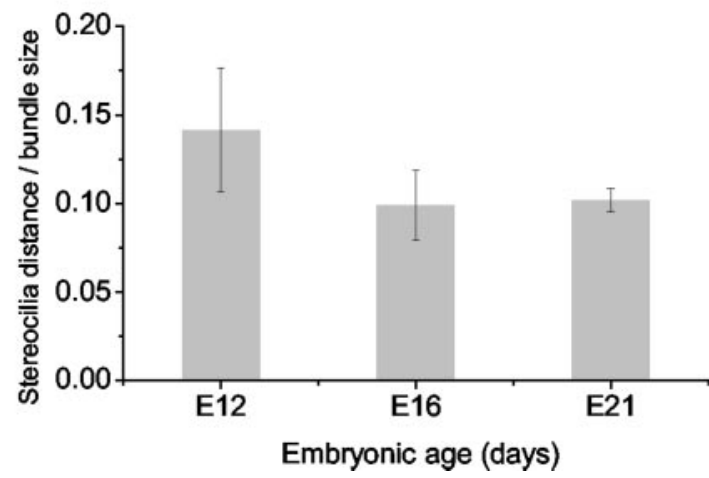

Figure 12. Ratio of angled tip links to normal tip links as a function of embryonic age. $A$, Angled tip links are linkages seen in scanning electron micrographs that do not run parallel to the axis of mirror symmetry. From E12 to E16, the relative number of angled tip links increased by $\sim 2.2$-fold and then declined at E21 by $\sim 1.9$-fold. Tip links at different embryonic age were counted in a blind manner by seven observers. Each observer counted angled and normal tip links on the same 42 bundles. For each bundle, the estimates of the seven observers were averaged; at each embryonic age, means \pm SEs derived from 11-20 bundles are reported. Comparisons of the ratios of angled tip links to normal tip links indicated that there were statistical significances between E12, E16, and E21 ( $p<0.05$ between all pairs of groups; one-way ANOVA). $B$, Ratio of the distance between adjacent stereocilia tips to the hair bundle size as a function of embryonic age. Hair bundle size was evaluated at the length of the shortest row of stereocilia. From E12 to E16, the relative distances between stereocilia tips decreased by $\sim 1.4$-fold and then remained relatively similar at E21. Measurements were performed in a blind manner by five observers. Twenty random measurements of the distance between adjacent stereocilia tips were made on each of the same 60 bundles. At each embryonic age, the measurements of the five observers were averaged, and means \pm SEs derived from 20 bundles on four basilar papillas are reported. $t$ test shows that $p<0.01$ between E12, E16 and E12, E21. There were no significant differences between E16 and E21 $(0.05<p<0.1)$.

embryonic age during development. On the basis of dye loading experiments, we suggest that some hair cells may be equipped to transduce mechanical displacements on E11. Previous experiments have also demonstrated that the development of hair bundles into the matured staircase pattern may entail sequential initiation, elongation, and capping of stereociliary actin and that the process may require the activity of transducer channels (Tilney et al., 1988). Our findings that the arrangement of the stereocilia into rows of ascending heights begins (Tilney and DeRosier, 1986) before the origin of transducer currents may suggest that transducer currents are not a prerequisite for the initiation of the development of the morphology of matured hair bundles. Indeed, the current, which can be generated when the first rank of stereocilia begins to elongate, is expected to be relatively small. It is conceivable, however, that mechanoelectrical transduction may regulate the assembly of the stereociliary bundle. Because the transducer channels are permeable to $\mathrm{Ca}^{2+}$ (Ohmori, 1985; Lumpkin et al., 1997) and because stereocilary $\mathrm{Ca}^{2+}$ may regulate the formation of tip links and perhaps other linkages (Zhao et al., 1996), the requirement of the transducer currents to promote 
further development of transduction machinery may be a plausible assertion (Tilney et al., 1988).

The number of stereocilia per a given hair cell may determine the number of mechanoelectrical transducer channels and hence the magnitude of transducer currents (Denk et al., 1995; Lumpkin and Hudspeth, 1995). Although hair cells from the basal portion of the chicken basilar papilla have $>200$ stereocilia per bundle, hair cells at the apical aspects have $<50$ stereocilia (Tilney and Saunders, 1983), suggesting that the transducer currents from the basal hair cells are expected to be larger than in apical hair cells. Our findings were in accord with this prediction during the early phase of embryonic development (E14 and E16), when the resting open probability of transducer channels has not reached the matured value, as shown in Figure $4 \mathrm{~B}$. On the basis of FM1-43 loading experiments, the resting transduction current in basal hair cells was significantly larger than the apical hair cells at E14 and E16. These results indicate that basal hair cells express more transducer channels than apical hair cells in
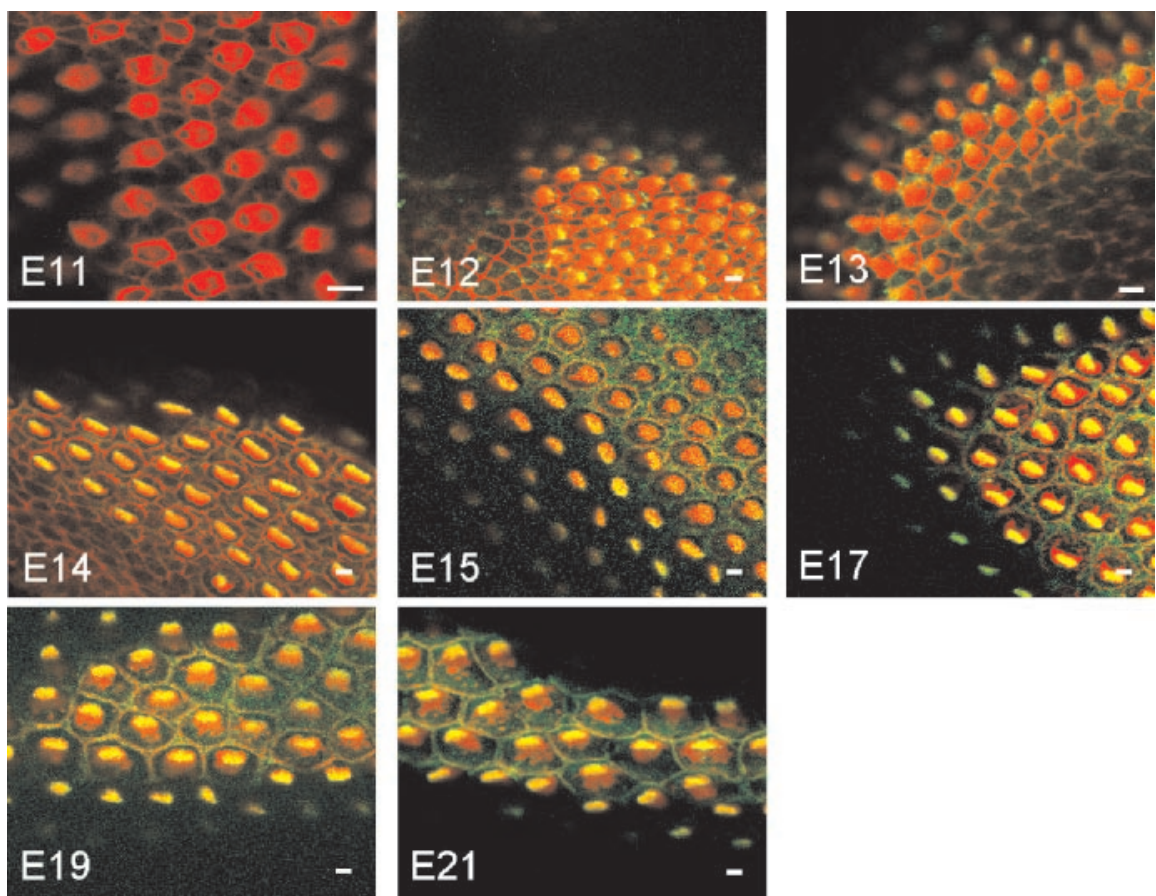

Figure 13. Localization of myosin 1c in the chicken basilar papillas at various developmental stages by immunofluorescence. All images were taken from the midsection of the abneural side of the basilar papillas. Confocal sections showing double staining with rhodamine-labeled phalloidin (red) and anti-myosin 1c (green) antibodies revealed that myosin 1c immunoreactivity was first observed at E12. early embryonic development. The results also suggest, however, that other factors such as increased resting tension in the tip links may be larger in apical than basal hair cells in a late phase of embryonic development because FM1-43 dye loading reflects both the resting $P_{\mathrm{o}}$ and the number of transducer channels.

In a recent preliminary report, Bryant et al. (2003) showed that mechanotransduction in chick papillary hair cells begins at embryonic-equivalent stage E8.5, ruling out the possibility that transducer current is a precondition for the initiation of development of the staircase structure of hair bundles. In this report, we observed that transducer current began at E11-12 using acutely isolated chick papillary hair cells as compared with in vitro culture preparations (Bryant et al., 2003). Similar to the development and differentiation of cells in other systems, hair cell differentiation may require positive and negative regulators, some of which may originate from intrinsic and extrinsic factors (Raff et al., 1998). Indeed, hair cell overproduction occurs in cultured mammalian cochlea, without any specific manipulation (Abdouh et al., 1993). Thus, in vitro culture conditions for the chick cochlea may accelerate the normal developmental process.

Previous studies have demonstrated that in lower vertebrates such as amphibians and avians, hair cell production occurs throughout life, in contrast to the mammalian auditory epithelia (Corwin and Cotanche, 1988; Ryals and Rubel, 1988). Recent reports, however, have suggested that hair cells in mammals have the potential to regenerate (Warchol et al., 1993; Li and Forge, 1997; Gao, 1999; Zheng et al., 1999; Zheng and Gao, 2000), given the appropriate stimulating factors (Xiang et al., 1998; Zheng and Gao, 2000). Because excessive noise, certain antibiotics, and normal aging cause hair cell loss in the auditory epithelia of both birds and mammals, except that in birds new hair cells replace those that degenerate (Ryals and Rubel, 1988; Balak et al., 1990), it is of great interest to understand the mechanisms of
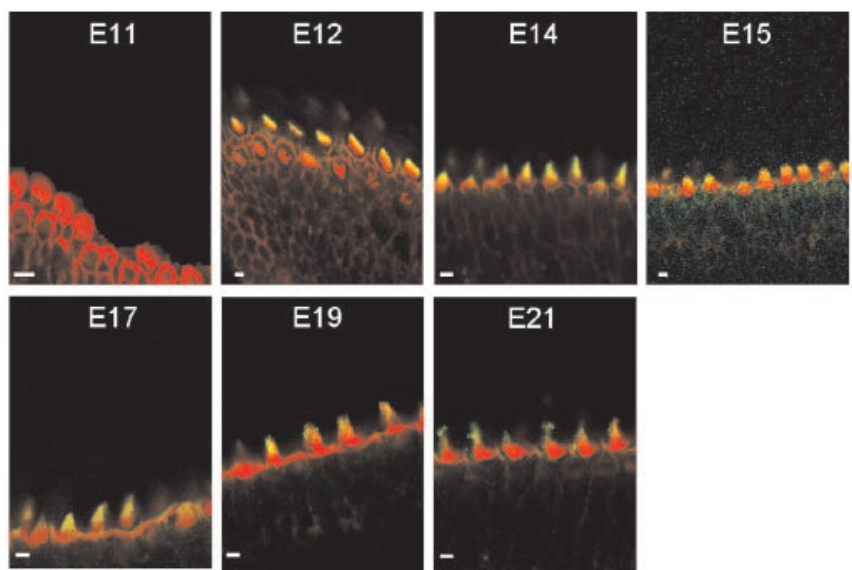

Figure 14. Longitudinal section of confocal images showing immunofluorescence labeling of myosin 1c in hair cells from the midsection of the abneural portion of a chicken basilar papilla from different embryonic ages. From E12 to E15, myosin-1c labeling was localized relatively diffusely along the length of the hair bundles; from E17 to E21, however, the positive labeling was more concentrated at the tips of the hair bundles in a punctate pattern. Scale bar, $5 \mu \mathrm{m}$.

hair cell regeneration in birds. We have demonstrated that the development of transducer currents involves systematic changes in the magnitude and kinetics of the current, suggesting that there is methodical recruitment and refinement of the transduction machinery. The precise temporal juxtaposition of myosin 1c and PMCA2 with the transducer currents may be fortuitous; however, it is reasonable to assert that these proteins render a hair cell capable of responding to mechanical stimulation. 

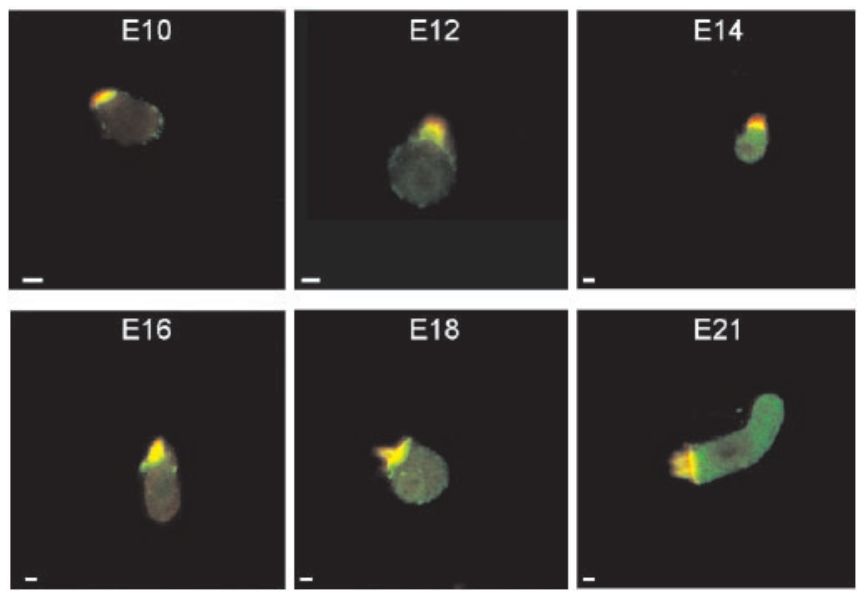

Figure 15. Immunocytochemical localization of myosin VIla in hair cells isolated from the midsection of the abneural segment of chicken basilar papillas observed at different embryonic ages. Red denotes actin, and green denotes myosin VIlla. From E10 to E21, myosin VIla-positive staining (green) was present throughout the cell, including the cuticular plate and the overlying hair bundle. Scale bars, $5 \mu \mathrm{m}$.
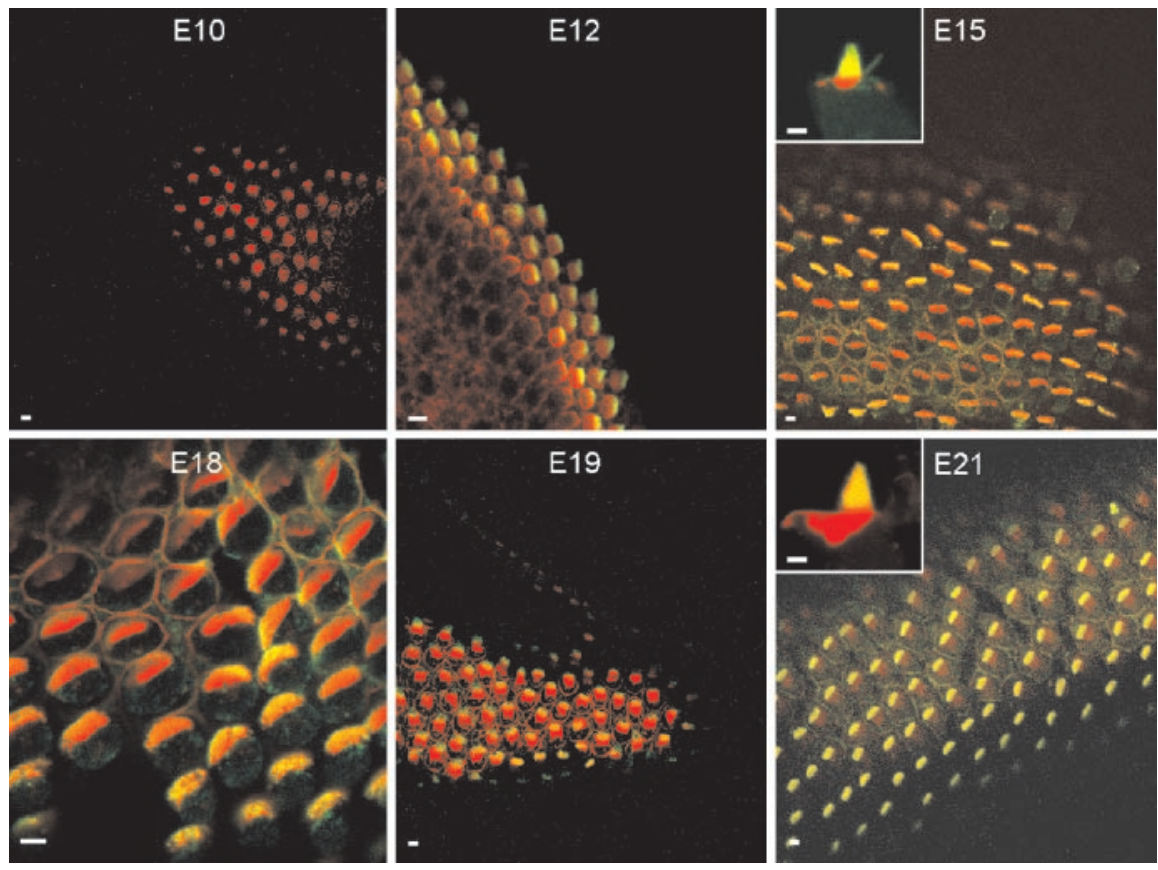

Figure 16. Localization of chicken basilar papilla PMCA2 by immunofluorescence. Shown are whole-mount views of the midsection of the abneural portion of basilar papilla. Intense immunoreactivity is present at the surface of stereocilia of hair cells, supporting the involvement of $\mathrm{Ca}^{2+}$ in regulating transduction and adaptation mechanisms. The insets are high magnifications of hair bundles at E15 and E21, respectively. Scale bars, $5 \mu \mathrm{m}$.

\section{References}

Abdouh A, Despres G, Romand R (1993) Hair cell overproduction in the developing mammalian cochlea in culture. NeuroReport 5:33-36.

Ashmore J, Richards CD (2002) FM1-43 reveals membrane recycling in adult inner hair cells of the mammalian cochlea. J Neurosci 3939-3952.

Assad JA, Shepherd GM, Corey DP (1991) Tip-link integrity and mechanical transduction in vertebrate hair cells. Neuron 7:985-994.

Balak KJ, Corwin JT, Jones JE (1990) Regenerated hair cells can originate from supporting cell progeny: evidence from phototoxicity and laser ablation experiments in the lateral line system. J Neurosci 10:2502-2512.

Bryant JE, Marcotti W, Kros CJ, Richardson G (2003) FM1-43 enters hair cells from the onset of mechano-electrical transduction in both mouse and chick cochlea. Assoc Res Otolaryngol 26:107.

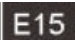

Cochilla AJ, Angleson JK, Betz WJ (1999) Monitoring secretory membrane with FM1-43 fluorescence. Annu Rev Neurosci 22:1-10.

Corwin JT, Cotanche DA (1988) Regeneration of sensory hair cells after acoustic trauma. Science 240:1772-1774.

Cotanche DA, Corwin JT (1991) Stereociliary bundles reorient during hair cell development and regeneration in the chick cochlea. Hear Res 52:379-402.

Cyr JL, Dumont RA, Gillespie PG (2002) Myosin-1c interacts with hair-cell receptors through its calmodulin-binding IQ domains. J Neurosci 22:2487-2495.

Denk W, Holt JR, Shepherd GM, Corey DP (1995) Calcium imaging of single stereocilia in hair cells: localization of transduction channels at both ends of tip links. Neuron 15:1311-1321.

Dumont RA, Lins U, Filoteo AG, Penniston JT, Kachar B, Gillespie PG (2001) Plasma membrane $\mathrm{Ca}^{2+}$-ATPase isoform 2a is the PMCA of hair bundles. J Neurosci 21:5066-5078.

Eatock RA, Corey DP, Hudspeth AJ (1987) Adaptation of mechanoelectrical transduction in hair cells of the bullfrog's sacculus. J Neurosci 7:2821-2836.

Fettiplace R (1992) The role of calcium in hair cell transduction. Soc Gen Physiol Ser 47:343-356.

Gale JE, Marcotti W, Kennedy HJ, Kros CJ, Richardson GP (2001) FM1-43 dye behaves as a permeant blocker of the hair-cell mechanotransducer channel. J Neurosci 21:7013-7025.

Gao WQ (1999) Role of neurotrophins and lectins in prevention of ototoxicity. Ann NY Acad Sci 884:312-327.

Garcia JA, Yee AG, Gillespie PG, Corey DP (1998) Localization of myosin-Ibeta near both ends of tip links in frog saccular hair cells. J Neurosci 18:8637-8647.

Gillespie PG, Wagner MC, Hudspeth AJ (1993) Identification of a $120 \mathrm{kd}$ hair-bundle myosin located near stereociliary tips. Neuron 11:581-594.

Griesinger CB, Richards CD, Ashmore JF (2002) Fm1-43 reveals membrane recycling in adult inner hair cells of the mammalian cochlea. J Neurosci 22:3939-3952.

Hamburger V, Hamilton HL (1992) A series of normal stages in the development of the chick embryo. Dev Dyn 195:231-272.

Hasson T, Gillespie PG, Garcia JA, MacDonald RB, Zhao Y, Yee AG, Mooseker MS, Corey DP (1997) Unconventional myosins in inner-ear sensory epithelia. J Cell Biol 137:1287-1307.

Holt JR, Corey DP (2000) Two mechanisms for transducer adaptation in vertebrate hair cells. Proc Natl Acad Sci USA 97:11730-11735.

Holt JR, Gillespie SK, Provance DW, Shah K, Shokat KM, Corey DP, Mercer JA, Gillespie PG (2002) A chemical-genetic strategy implicates myosin-1c in adaptation by hair cells. Cell 108:371-381.

Hudspeth AJ (1992) Hair-bundle mechanics and a model for mechanoelectrical transduction by hair cells. Soc Gen Physiol Ser 47:357-370.

Hudspeth AJ, Gillespie PG (1994) Pulling springs to tune transduction: adaptation by

hair cells. Neuron 12:1-9.

Kachar B, Parakkal M, Kurc M, Zhao Y, Gillespie PG (2000) Highresolution structure of hair-cell tip links. Proc Natl Acad Sci USA 97:13336-13341.

Kros CJ, Marcotti W, van Netten SM, Self TJ, Libby RT, Brown SD, Richardson GP, Steel KP (2002) Reduced climbing and increased slipping adaptation in cochlear hair cells of mice with Myo7a mutations. Nat Neurosci 5:41-47.

Li L, Forge A (1997) Morphological evidence for supporting cell to hair cell conversion in the mammalian utricular macula. Int J Dev Neurosci 15:433-446.

Lumpkin EA, Hudspeth AJ (1995) Detection of $\mathrm{Ca}^{2+}$ entry through mech- 
anosensitive channels localizes the site of mechanoelectrical transduction in hair cells. Proc Natl Acad Sci USA 92:10297-10301.

Lumpkin EA, Marquis RE, Hudspeth AJ (1997) The selectivity of the hair cell's mechanoelectrical-transduction channel promotes $\mathrm{Ca}^{2+}$ flux at low $\mathrm{Ca}^{2+}$ concentrations. Proc Natl Acad Sci USA 94:10997-11002.

McNiven AI, Yuhas WA, Fuchs PA (1996) Ionic preference of an acetylcholine receptor in hair cells. Aud Neurosci 2:63-77.

Meyers JR, MacDonald RB, Duggan A, Lenzi D, Standaert DG, Corwin JT (2003) Lighting up the senses: FM1-43 loading of sensory cells through nonselective ion channels. J Neurosci 23:4054-4065.

Ohmori H (1985) Mechano-electrical transduction currents in isolated vestibular hair cells of the chick. J Physiol (Lond) 359:189-217.

Pickles JO, Comis SD, Osborne MP (1984) Cross-links between stereocilia in the guinea pig organ of Corti, and their possible relation to sensory transduction. Hear Res 15:103-112.

Pickles JO, Osborne MP, Comis SD (1987) Vulnerability of tip links between stereocilia to acoustic trauma in the guinea pig. Hear Res 25:173-183.

Raff MC, Durand B, Gao FB (1998) Cell number control and timing in animal development: the oligodendrocyte cell lineage. Int J Dev Biol 42:263-267.

Rodriguez-Contreras A, Yamoah EN (2001) Direct measurement of singlechannel $\mathrm{Ca}(2+)$ currents in bullfrog hair cells reveals two distinct channel subtypes. J Physiol (Lond) 534:669-689.

Rodriguez-Contreras A, Yamoah EN (2003) Effects of permeant ion concentrations on the gating of L-type $\mathrm{Ca}^{2+}$ channels in hair cells. Biophys J 84:3457-3469.

Rodriguez-Contreras A, Nonner W, Yamoah EN (2002) $\mathrm{Ca}^{2+}$ transport properties and determinants of anomalous mole fraction effects of single voltage-gated $\mathrm{Ca}^{2+}$ channels in hair cells from bullfrog saccule. J Physiol (Lond) 538:729-745.

Russell IJ, Richardson GP, Kössl M (1989) The responses of cochlear hair cells to tonic displacements of the sensory hair bundle. Hear Res 43:55-69.

Ryals BM, Rubel EW (1988) Hair cell regeneration after acoustic trauma in adult Coturnix quail. Science 240:1774-1776.

Saunders JC, Szymko YM (1989) The design, calibration, and use of a water microjet for stimulating hair cell sensory hair bundles. J Acoust Soc Am 86:1797-1804.

Saunders JC, Coles RB, Gates GR (1973) The development of auditory evoked responses in the cochlea and cochlear nuclei of the chick. Brain Res 63:59-74.

Tilney LG, DeRosier DJ (1986) Actin filaments, stereocilia, and hair cells of the bird cochlea. IV. How the actin filaments become organized in developing stereocilia and in the cuticular plate. Dev Biol 116:119-129.

Tilney LGS, Saunders JC (1983) Actin filaments, stereocilia, and hair cells of the bird cochlea. I. Length, number, width, and distribution of stereocilia of each hair cell are related to the position of the hair cell on the cochlea. J Cell Biol 96:807-821.

Tilney LG, Tilney MS, Cotanche DA (1988) Actin filaments, stereocilia, and hair cells of the bird cochlea. V. How the staircase pattern of stereociliary lengths is generated. J Cell Biol 106:355-365.

Vazquez AE, Yamoah EN (2002) Mechanisms of hair cell mechanoelectric transduction: an update. Curr Opin Otolaryngol Head Neck Surg 10:403-406.

Warchol ME, Lambert PR, Goldstein BJ, Forge A, Corwin JT (1993) Regenerative proliferation in inner ear sensory epithelia from adult guinea pigs and humans. Science 259:1619-1622.

Wu SN, Lin PH, Hsieh KS, Liu YC, Chiang HT (2003) Behavior of nonselective cation channels and large-conductance $\mathrm{Ca}^{2+}$-activated $\mathrm{K}^{+}$channels induced by dynamic changes in membrane stretch in cultured smooth muscle cells of human coronary artery. J Cardiovasc Electrophysiol 14:44-51.

Wu YC, Ricci AJ, Fettiplace R (1999) Two components of transducer adaptation in auditory hair cells. J Neurophysiol 82:2171-2181.

Xiang M, Gao WQ, Hasson T, Shin JJ (1998) Requirement for Brn-3c in maturation and survival, but not in fate determination of inner ear hair cells. Development 125:3935-3946.

Yamoah E (2001) Plasma membrane $\mathrm{Ca}^{2+}$-ATPase mediates a transcellular $\mathrm{Ca}^{2+}$ efflux in bullfrog sacculus. Assoc Res Otolaryngol Abstr 24:21908.

Yamoah EN, Gillespie PG (1996) Phosphate analogs block adaptation in hair cells by inhibiting adaptation-motor force production. Neuron 17:523-533.

Yamoah EN, Lumpkin EA, Dumont RA, Smith PJ, Hudspeth AJ, Gillespie PG (1998) Plasma membrane $\mathrm{Ca}^{2+}$-ATPase extrudes $\mathrm{Ca}^{2+}$ from hair cell stereocilia. J Neurosci 18:610-624.

Zhao Y, Yamoah EN, Gillespie PG (1996) Regeneration of broken tip links and restoration of mechanical transduction in hair cells. Proc Natl Acad Sci USA 93:15469-15474.

Zheng JL, Gao WQ (2000) Overexpression of Math1 induces robust production of extra hair cells in postnatal rat inner ears. Nat Neurosci 3:580-586.

Zheng JL, Frantz G, Lewis AK, Sliwkowski M, Gao WQ (1999) Heregulin enhances regenerative proliferation in postnatal rat utricular sensory epithelium after ototoxic damage. J Neurocytol 28:901-912. 